\title{
IS THERE ONE OR TWO THERES?
}

\section{A Look at Existential and Locative There}

\author{
Mémoire présenté \\ à la Faculté des études supérieures de l'Université Laval \\ comme exigence partielle du programme de maîtrise en linguistique \\ offert à l'Université du Québec à Chicoutimi \\ en vertu d'un protocole d'entente avec l'Université Laval \\ pour l'obtention du grade de maître ès arts (M. A.)
}

\author{
FACULTÉ DES LETTRES \\ UNIVERSITÉ LAVAL \\ QUÉBEC \\ et
}

DÉPARTEMENT DES ARTS ET LETTRES

UNIVERSITÉ DU QUÉBEC À CHICOUTIMI

SAGUENAY

AVRIL 2004

(C) Diana Coonrod, 2004 


\section{Bibliothèque}

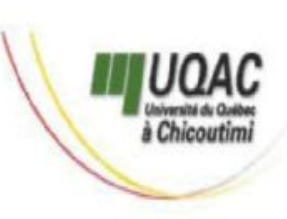

\section{Mise en garde/Advice}

Afin de rendre accessible au plus Motivated by a desire to make the grand nombre le résultat des results of its graduate students' travaux de recherche menés par ses research accessible to all, and in étudiants gradués et dans l'esprit des accordance with the rules règles qui régissent le dépôt et la governing the acceptation and diffusion des mémoires et thèses diffusion of dissertations and produits dans cette Institution, theses in this Institution, the I'Université du Québec à Université du Québec à Chicoutimi (UQAC) est fière de Chicoutimi (UQAC) is proud to rendre accessible une version make a complete version of this complète et gratuite de cette œuvre. work available at no cost to the reader.

L'auteur conserve néanmoins la The author retains ownership of the propriété du droit d'auteur qui copyright of this dissertation or protège ce mémoire ou cette thèse. thesis. Neither the dissertation or Ni le mémoire ou la thèse ni des thesis, nor substantial extracts from extraits substantiels de ceux-ci ne it, may be printed or otherwise peuvent être imprimés ou autrement reproduced without the author's reproduits sans son autorisation. permission. 


\section{RÉSUMÉ}

Dans la littérature, il est souvent soutenu que le there existentiel et le there locatif sont deux mots distincts en raison de caractéristiques divergentes sur les plans sémantiques, phonologiques et syntaxiques. Par contre, d'autres caractéristiques à ces mêmes niveaux suggèrent plutôt que ces deux emplois ne sont que des variantes du même mot. Ceci a donné lieu à deux interprétations de la notion de there, un problème fondamental et non résolu qui est le sujet de ce mémoire. Dans le présent travail, ce problème est abordé dans la perspective de la linguistique guillaumienne où la signification d'un mot est conçue comme un potentiel sous-jacent pouvant se réaliser dans le discours avec diverses actualisations de ce signifié de puissance.

Il est proposé dans ce mémoire que la clef de la problématique du there, qui a fait l'objet de nombreuses recherches au cours des trente dernières années, se trouve dans une meilleure compréhension du there locatif. On y trouve que le comportement du there locatif n'est pas assimilable à celui d'un pronom, et qu'il ne fonctionne pas par substitution. En fait, le there locatif s'explique le mieux en terme d'un processus associatif tripartite plutôt qu'un du processus bipartite caractéristique des pronoms. Plus précisément, le there locatif (1) s'associe avec des référents, (2) qui reconfigurent son espace encore indéfini, (3) ce qui amène à la création d'un lieu où entrent en scène des événements ou des entités. On développe dans ce mémoire un modèle du processus associatif qui rend compte non seulement de l'utilisation concrète de l'espace, mais aussi de la capacité fonctionnelle du there existentiel, montrant ainsi que les deux emplois de there partagent la même capacité fonctionnelle.

Un des arguments principaux en faveur de la thèse des deux there est que le there locatif porte toujours un accent tonique alors que le there existentiel n'en porte pas. Toutefois, on montre ici l'existence de paires minimales mettant deux there en contraste dans la construction verbe + there au niveau discursif, ce qui suggère que l'accent tonique est un élément contrastif signalant une variation de sens. Dans cette construction, le there accentué (par exemple, sit there) crée un espace défini alors que le there non accentué (par exemple, sit there) donne lieu à un espace de nature plus subjective. Ces paires phonologiques à démarcation sémantique sont similaires à l'opposition entre le there locatif et le there existentiel dans l'inversion, ce qui est une preuve de l'existence d'un système où le there existentiel n'est rien de plus qu'un emplois particulier d'un signifié de puissanciell sous-jacent.

Sur le plan sémantique, there locatif est beaucoup plus diversifié qu'on le croyait, car

il a la capacité de configurer non seulement un sens locatif ou temporel, mais peut 
également exprimer diverses abstractions relatives à l'espace. De plus, there locatif peut évoquer d'autres significations de nature subjective, comme celle de "l'occupation minimale d'un espace » défini par l'action. Également, la réalisation de notions de «présence » et "d'existence » est possible, de même que diverses combinaisons de ces significations. Sémantiquement, ceci suggère l'existence d'une seule potentialité sousjacente du sens de there, avec une capacité de réaliser un éventail étendue de sens, allant d'emplois référentiels objectifs à d'autres plus subjectifs, modifiables par le contexte, la syntaxe et l'accentuation. 


\section{ABSTRACT}

In the literature, it is often argued that existential there and locative there are two distinct words because of distinguishing features at semantic, phonological and syntactic levels. However, other features at these same levels also suggest that the two uses are polysemic variations of a single word. This has led to two opposite interpretations of the nature of there which is the basic unresolved problem that has inspired this study. The problem is approached from the Guillaumian perspective which views meaning as an underlying potential with a capacity to realize various extensions in actualized speech acts.

It is argued herein that the problem of there, which has been the object of numerous studies over the last 30 years, can only be resolved in light of a more complete understanding of locative there. Locative there is shown not to function by substitution and to behave distinctly from pronouns. Its behavior is best accounted for in a tripartite associative process rather than the bipartite referring process common to pronouns. That is, locative there (1) associates with referents that (2) serve to reconfigure its undefined space, which in turn, (3) provides a place wherein events or entities can be situated. It is found that the Model of the Associative Process proposed herein reflects not only the use of space in real life but also the functional capacity of existential there, thus establishing the same functional capacity for both uses of there.

A major argument for considering both uses of there distinct words is that locative there is purported to always be stressed, whereas existential there is unstressed. However, minimal pairs in the Verb + there discourse construction were discovered suggesting that stress is contrastive and signals meaning differences. In this construction, a stressed there (e.g. sit there) configures a particular space whereas an unstressed there (e.g. sit there) configures a more subjective type of space. These meaning-distinct phonological pairs are comparable to the locative/existential there opposition which occurs in the inversion construction providing evidence of a system in which existential there is but a single use of a single underlying meaning potential.

From the point of view of meaning, locative there is much more diversified than generally thought. Not only can it configure locative and temporal meaning, but it can express various abstractions of space. In addition, 'locative' there can be used to evoke more subjective types of meaning, such as the 'mere occupation of space.' Furthermore, notions of 'presence' and 'existence' can be realized, as well as various combinations of senses. Semantically, this suggests a single underlying meaning potential with the capacity to express a wide range of meanings that are conditioned by syntax, stress, and context, extending all the way from objective referential uses to more subjective senses. 


\section{ACKNOWLEDGEMENTS}

Much to the amazement of many, the word there provided enough of a challenge to fuel my gray cells all the years it has taken to finish this thesis. There was an incredible amount of information to wade through and digest, and I could not have done it without the encouragement and help of many people.

First, I would first like to thank my thesis director Dr. Patrick Duffley who, with calm and patience, pointed to some pertinent new directions this thesis had to take. Much appreciated were his delicate and precise editing skills, his intellectual openness and integrity and his generous availability throughout all these years. A finer thesis director, I could not have asked for.

I would also like to thank Lori Morris who got me started on this project. Not only did she believe in the Guillaumian theory, but she believed I had it in me to bring new things to light and the project to term.

To my fellow colleague and friend, Leif French, thanks for being there. You provided me with precious input, some authentic tokens, and shared in the ups and downs of such a project. I also wish to thank Dr. Dolbec and Dr. $\mathrm{M}^{\mathrm{c}} \mathrm{Creesh}$ at l'Université du Québec à Chicoutimi. I am also deeply indebted to those researchers who have gone before me whose studies have helped shape and mold the direction this thesis has finally taken.

As a linguist, my husband was always a willing listener and participant in the many discussions that there generated in our household; he shared with joy as I discovered new findings and encouraged me when the going got tough. Merci du fond du cour. To my sons, thanks for sharing your mama with the existent but not so palpable there, and for being second in line for computer use. And to Johanne, thanks for helping me with the sometimes frustrating niceties of modern technology.

And finally, it is with deepest gratitude that I thank my parents who instilled in me a curiosity for the world around me, who got me thinking and discussing at an early age and taught me to continue to the very end. 


\section{TABLE OF CONTENTS}

\section{CHAPTER 1 DEFINITIONS OF TERMS I NOTATIONAL CONVENTIONS 1}

1.1 Terminology 1

1.2 Notational conventions 3

CHAPTER 2 THE PROBLEM 5

2.1 The basic problem: Is there one or are there two THERES? 5

2.2 The problem in more detail 6

2.2.1 The distinguishing features of existential and locative there 6

2.2.1.1 Syntactic differences $\quad 6$

2.2.1.2 Semantic differences $\quad 8$

2.2.1.3 Phonological differences 10

2.2.1.4 Participation in a binary opposition with here 10

2.2.1.5 The differences: a conclusion 11

2.2.2 Unifying features 11

2.2.2.1 Single graphic representation $\quad 12$

2.2.2.2 Syntactic similarities/similar discourse constructions 12

2.2.2.3 Semantic similarities 19

2.2.3 The neglect of locative there 21

2.2.4 Conclusion $\quad 22$

CHAPTER 3 THEORETICAL FRAMEWORK 23

$\begin{array}{ll}\text { 3.1 The Theory } & 23\end{array}$ 
3.4 Model of the Associative Potential 28

3.4.1 The underlying dynamics of space 28

3.4.2 Description of the Associative Process 29

CHAPTER 4 DISCUSSION 34

4.1 The Associative Function of there 34

4.1.1 The inadequacy of substitution to explain the function of locative there 34

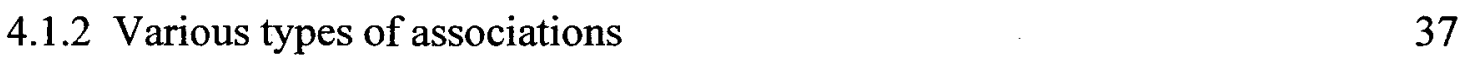

4.1.2.1 'Classic' anaphoric associations with spatial referents 37

4.1.2.2 Temporal associations: the construction of temporal space 38

4.1.2.3 Temporal-narrative associations: Temporal-narrative space 41

4.1.2.4 Pragmatic associations 42

4.1.2.5 There + PP — cataphoric associations? 42

4.1.2.6 The associative function of locative there summarized 47

4.1.3 The functional correlation between locative and existential uses of there 47

4.2 The role of stress in the realizations of there 52

4.2.1 What pronoun stress reveals about the phonological realization of locative there 53

4.2.2 Stress phenomena as it relates to a new discourse structure, 'verb + there,' a link to existential there $\quad 56$

4.3 Are there two uses of there in other syntactic constructions?

4.3.1 Preposed-there $\quad 64$

4.3.2 More cases of unstressed there $\quad 69$

$\begin{array}{ll}4.3 .3 \text { Conclusion } & 70\end{array}$ 


\subsection{The Semantics of there}

4.5.1 The VERB + THERE construction: non- $b e$ verbs versus $b e$ verbs 75

4.5.2 ' $b e$ ' + there evoking presence: another link to the existential use of there 76

4.5.3 Simple forms of be there: the neutralization of meaning and stress $\quad 79$

4.5.4 Other cases of 'locative' there and be expressing existence 82

4.5.5 The meaning of the existential use of there and its relationship to SAI 83

4.5.6 The semantics of the potential meaning of there 83

CHAPTER 5 CONCLUSION $\quad 86$

REFERENCES 


\section{LIST OF TABLES}

Table 1: A Comparison of Two Discourse Constructions 63

Table 2: Semantically Light There in Three Discourse Constructions 72

Table 3: Particularizing There in Three Discourse Constructions 73 


\section{LIST OF FIGURES}

Figure 1: The Non-constructed Open Space 30

Figure 2: Association with a Referent 30

Figure 3: Reconfiguration of Container Space to Referent 31

Figure 4: Connection to an Entity or an Event 32

Figure 5: Model of the Associative Potential of There 33

Figure 6: The Associative Potential as Reflected in the Existential Use of There 49

Figure 7: The Connective Capacity of Locative and Existential There 50 


\section{CHAPTER 1}

\section{DEFINITIONS OF TERMS / NOTATIONAL CONVENTIONS}

The purpose of this brief chapter is to define some of the terms and give the notational conventions used in this study. This will serve, first, as a point of reference and second, as a way to facilitate the reading of this thesis. Furthermore, terminology used in linguistic literature can have varying definitions depending on the theoretical approach. As such, the definitions given here are intended to eliminate confusion or misunderstandings in the text.

\subsection{Terminology}

- CÄNONICAL-WORD ORDER: are those constructions whose syntactic word order is 'standard' in the sense of subject-verb-object (SVO) ordering, and which function at the level of discourse as the mere assertion of a truth.

- INVERSION: is a discourse construction also known as Full Inversion (Dorgeloh 1997; Penhallurick 1984; Duffley 1999). It has been defined as "those declarative constructions where the subject follows part or all of its verb phrase" (Green 1982: 120 in Dorgeloh 1997: 20):

Example:

$<$ As interesting $>$ are $<$ the classics, the contemporary, and the unexpected books. $>$

- LOCATIVE INVERSION: is a subset of inversion. The construction's pre-verbal constituent is semantically locative, usually in the form of a prepositional phrase:

Example:

$<$ Through the crack $>$ came $<$ the wind and snow. $>$ 
- THERE-INVERSION: is a subset of inversion in which the fronted item is either an existential or a locative use of there. Inversions with the existential use of there are also known as the existential there construction.

Example with a locative use of there:

$<$ There, at the end of the pier $>$ was $<$ a most beautiful sunset. $>$

Example with an existential use of there:

$<$ There $>$ was $<$ a stillness, an immense silence. $>$

- PREPOSING: is a discourse construction characterized syntactically by a subject that is preceded by "some constituent that would canonically stand behind the verb" (Dorgeloh 1997: 54).

Examples:

a. There, they captured 11 men.

b. Into the woods, Goldilocks skipped merrily singing a happy song.

- GIVEN/NEW INFORMATION: is an opposition of relative familiarity of discourse information. It corresponds to the theme/rheme distinction within the Praguian theory of communicative dynamism (Firbas 1966; Hartvigson \& Jakobsen 1974).

- ASSOCIATION: describes the relationships of a referring expression. The term replaces the standard terms of "referring" or "referencing" which at some point in the analysis of there became too limited to describe the relationships which there entertains.

- ANAPHOR/ANAPHORIC ASSOCIATIONS: associations that referring expressions such as there make with a referent or referent expression in the preceding text or in the 'given' situational context.

- CATAPHOR/CATAPHORIC ASSOCIATIONS: associations that referring expressions such as there make with a referent/referent expression in the text that follows.

- CONTEXT/CONTEXTUAL ASSOCIATIONS: subsumes both co-textual and situational referencing.

- CO-TEXT/CO-TEXTUAL ASSOCIATIONS: those associations that involve in-text referents, whether anaphoric or cataphoric. 
- SitUATIONAL ASSOCIATIONS: those associations made with referents that are in the situational environment and not part of the linguistic environment.

- PRAGMATIC ASSOCIATIONS: those associations made via inferences involving knowledge of the world.

- ACTUALIZATION/REALIZATION/APPLICATIONS: synonymous terms used within the Guillaumian theory to signify the sense of the word in written or spoken discourse. These terms are in opposition to 'potential meaning' which is the underlying base meaning.

- REFERENT/REFERENT EXPRESSION: those constituents that participate in re-configuring the space of there (or other referring expressions) to evoke an actualized meaning in spoken or written speech acts.

\subsection{Notational conventions}

The following standard conventions are used in this thesis:

- * is the standard symbol used to designate syntactic unacceptability.

- ? is the symbol which designates a questionable linguistic segment. It does not carry as absolute a commentary as the asterisk.

- $\quad<>$ are the symbols used to highlight the pre-verbal and post-verbal constituents of inversion structures.

- PVNP is the acronym used for post-verbal noun phrase of non-canonical sentences, such as inversion and existential there constructions.

- Pre-VNP is used to indicate a pre-verbal noun phrase in a sentence involving inversion.

- $\quad \mathrm{NP}=$ noun phrase.

- $\quad \mathrm{PP}=$ prepositional phrase. 
- $\mathrm{SAI}$ is the acronym for subject-auxiliary inversion. 


\section{CHAPTER 2}

\section{THE PROBLEM}

\subsection{The basic problem: Is there one or are there two THERES?}

This thesis proposes to study a problem which revolves around one little English word: there. A little word, indeed, nonetheless quite a significant one if one considers the numerous linguistic discussions over the past thirty some years discussing the various facets of its complex nature. ${ }^{1}$ However, compared to the complexity of the nature of there and of the proposed solutions to the problem, the question is simple. It boils down to a question of categorization: are the two uses attributed to the word there inherently related or are they distinct? That is, is the adverbial locative there in some way related to what is commonly called existential there, or are the two uses illustrated in examples (1) and (2) "quite different words," as portrayed by Swan (1991: 290, 600)?

(1) LOCATIVE THERE: Bruno was not unhappy there at Wain college. [Golding 1939:50]

(2) EXISTENTIAL THERE: There's no better shirt when your boy needs a quick cool down. [Land's End Kid's Catalogue, Spring 1999, p 39]

In sum, the question is whether locative there and existential there are homophones or polysemic realizations of a single word. This problem provides the impetus behind this study which

\footnotetext{
1 "Perhaps nowhere else do we find so clearly displayed the complexity and subtlety of the syntactic and semantic interactions which determine the nature of human language as we do in existentials." (Milsark 1979: 10).
} 
takes a meaning-based theoretical perspective that views morpho-lexical form as having the function of signifying meaning. Thus the purpose of this study is to discover whether the two uses of there are realizations of one and the same meaning potential or whether two distinct theres must be postulated.

\subsection{The problem in more detail}

Essentially, the problem arises from the fact that there are two distinct uses attributed to a single graphic representation THERE, one of which could be called locative adverbial and the other existential. Both uses can be distinguished at syntactic, semantic and phonological levels, and in turn, these distinguishing features provide evidence for a 'distinction position' according to which the two uses are not one and the same word, but actually homophones. Nevertheless, there are also features that suggest that the two uses may be polysemic realizations of the same underlying meaning potential. Not only do the two uses share a unique graphic representation, but there are similarities at the syntactic and semantic levels providing the basic arguments for the 'relatedness position,' which holds that both theres are inherently a single word.

Hence, the following sections will marshal the evidence for the two basic positions of the problem. First discussed are how the two uses are distinct in terms of syntactic, phonological and semantic features, and in terms of the binary opposition between there and here. Secondly, the features common to both uses are discussed. Finally, the discussion will turn to the question of why the problem of there has remained unsolved.

\subsubsection{The distinguishing features of existential and locative there}

\subsubsection{Syntactic differences}

Existential there and locative there are syntactically distinct in two major ways. First of all, locative there can occupy different syntactic positions in a sentence, whereas existential there is 
restricted to a pre-verbal position, whether it be sentence-initial, in embedded clauses, or preceded by a preposed prepositional phrase:

(3) LOCATIVE THERE:

INITIAL POSITION: There on that table is your wallet.

MEDIAL POSITION: Your wallet is there on that table.

FINAL POSITION: Your wallet is on that table there.

(4) EXISTENTIAL THERE:

SENTENCE-INITIAL: There are many different Inuit nations, [...] [Joosse 1991]

EMBEDDED CLAUSE: There was a time when there were few luxury items available for the wealthy.

PREPOSED PREPOSITIONAL PHRASE: Against her thundering authority there was no appeal. [Wayson 1995: 185]

Secondly, existential there participates in subject-auxiliary inversion (henceforth SAI), in negations, in yes/no- and wh-questions, in question tags, and in conditionals, whereas locative there is unable to undergo SAI:

(5) LOCATIVE THERE:

NEGATION: *Never was in the corner there a bookcase.

YES/NO QUESTION: *Is there on the table your wallet?

WH QUESTION: *Why are in the corner there so many boxes?

TAG QUESTION: *There on the table is your wallet, isn't there?

CONDITIONAL: *Had there on the table been your wallet, I would have noticed it. 


\section{(6) EXISTENTIAL THERE:}

NEGATION: Never was there adequate equipment, supplies and enough personnel.

YES/NO QUESTION: Are there many different Inuit nations?

WH QUESTION: Why are there many different Inuit nations?

TAG QUESTION: There are many Inuit nations, aren't there?

CONDITIONAL: Had there been no formal demand, Nunavut would never have become a nation.

This syntactic divergence of locative and existential there gives rise to a problem of classification. On the one hand, locative there is generally and simply classified as an adverb. ${ }^{2}$ Existential there, in contrast, seems to defy definite categorization. Syntactic evidence such as subject-auxiliary inversion suggests that existential there may be a subject noun phrase since only noun phrases (NPs) undergo SAI. Discourse-level evidence, however, suggests it may be an adverbial scene-setting element similar to the preposed prepositional phrase (PP) of the locative inversion construction. (The similarities of these two discourse constructions are discussed in detail in section 2.2.2.2). Milsark has described existential there as a "theoretician's nightmare" (1979a: 99), which is indeed evidenced in the contradictory interpretations of existential there and the ensuing categorization problems.

\subsubsection{Semantic differences}

In addition to the syntactic differences observed above, the two theres also differ semantically. According to the general definition of adverbs given by The Grammar Book, "adverbs [...] contribute meaning of various sorts to sentences" (Celce-Murcia \& Larsen-Freeman 1999: 18), and locative there realizes "a spatial relation" (Quirk et al. 1985: 516) conventionally defined as in, at, or to that place or position (Swan 1995: 589; Swannell, ed., 1992: 495; Thatcher et al. 1971: 869 ) or "in a place other than that of the speaker" (Britannica World Language Dictionary 1961:

\footnotetext{
${ }^{2}$ Locative there has also been identified as a pronoun: "Pronouns occur in a number of different syntactic categories [...] There are also the pronouns here, there, therefore, [...]" (Hausser 1979: 97). The reason for this identification is that, like pronouns in the classical sense, there-adverbs are considered substitutes for other contextual constituents that are semantically related.
} 
1302). Existential there, by contrast, is reputed to be "semantically empty" (Milsark 1974: 24-25) or "relatively content-free" (Legget et al. 1991: 266) because it carries "none of the locative meaning of the adverb there" (Quirk et al. 1985: 1405, 1408). The idea that existential there is meaningless, which has been around for a long time, ${ }^{3}$ has given rise to the concept that it is a "compensatory device" which "can be dispensed with" (Breivik 1981: 7, 11). Indeed, Quirk suggests that existential there plays the role of a "dummy element" (1985: 1405, 1408), a notion that has been reiterated in various forms in grammars and writers' handbooks, ${ }^{4}$ dictionaries (Webster's Dictionary of English Usage 1989: 899) and in linguistic discussions (Breivik 1981: 15, 1983: 156; Birner 1992: 38, 1996: 24; Dorgeloh 1997: 52; Jespersen 1949: 107; Kuno 1971: 377). This has even led some commentators to theorize about the type of language capable of generating such an empty place-holder element:

According to Li \& Thompson (1976), such a pronoun [existential there] can only be found in a highly grammaticalized subjectpredicate language such as French or English. Because these languages always need a grammaticalized subject, the pronoun there is used as a 'filler' for the subject position when the position is empty. (Sasaki 1991: 158)

Even those who claim that existential there is inherently a locative do not argue against the fact that it is semantically light. Bolinger, for example, is well known for his position that the two theres share some inherent meaning, and he uses the expression "to tease out the true sense of there" (1977: 91), which implies that the meaning of existential there is not self-evident. Hence,

\footnotetext{
${ }^{3}$ Priestly (1761) and Webster (1828) both say in effect that existential there is meaningless. An excerpt from An American Dictionary of the English Language clearly expresses this notion: "There is used to begin sentences, or before a verb; sometimes pertinently, and sometimes without signification; but its use is so firmly established that it cannot be dispensed with." (Webster 1828: Vol. II).

${ }^{4}$ In Tools for Writers (1986), Thury writes "[existential there] is a blank phrase [that] does not add anything to the point you are trying to make in your paper." For a more complete study on how writers' handbooks have "oversimplified and even misconceived" the use of existential there see Huckin and Hutz-Pesante's article "Existential There" (1988).
} 
from the point of view of reference to the extra-mental world, it is undeniable that the two uses of there differ in terms of referential capacity. ${ }^{5}$

\subsubsection{Phonological differences}

A third way in which existential there and locative there differ is phonologically. The two theres are stressed differently which, consequently, phonetically alters the medial vowel. The there of existential sentences generally lacks stress and is pronounced /ðə(r)/, whereas locative there is

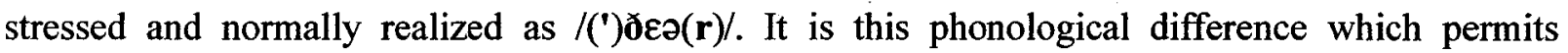
listeners to recognize which there is being used in the following ambiguous sentence:

(7) AMBIGUOUS SENTENCE : There's a man I want to see.

UNSTRESSED EXISTENTIAL THERE: There's a man I want to see.

(this man exists but he is not here)

STRESSED LOCATIVE THERE: There's a man I want to see. (he's standing at the door)

Here, the non-stressed version simply evokes the existence of a man to be seen who is not present, while the stressed there (indicated by bold type) points spatially to a man who is physically present. This phonological distinction is well attested in the literature (Allan 1971: 5; Breivik 1983: 173; Celce-Murcia \& Larsen-Freeman 1999: 446; Dorgeloh 1997: 52; Jespersen 1949: 107) and is regularly used as a feature to distinguish the two theres.

\subsubsection{Participation in a binary opposition with here}

Finally, one last distinction between the two uses of there is that locative there forms a binary system with here, a meaning-opposition whereby here evokes spatial relations that are speaker-

\footnotetext{
5 This is "semantic" only if one takes the term to mean "definable in terms of truth conditions or reference," as Milsark does. We will not be adopting this restrictive view of semantics.
} 
centered, and there spatial relations outside of reference to the speaker. ${ }^{6}$ A similar opposition between an existential there and here does not seem to obtain, and as a result, this observation is used as an additional argument that favors analyzing existential and locative there as distinct words (Allan 1971: 5). In the same line, Celce-Murcia and Larsen-Freeman (1999: 447) propose the "deictic here test (substitute here for there)" to determine if a there is existential or locative since "deictic here can alternate with deictic there, but not with non-referential there."

\subsubsection{The differences: a conclusion}

In summary, it has been observed that there are clear differences in the two realizations of there. First, existential there functions syntactically in a particular fashion: it is limited to pre-verbal position and undergoes subject-auxiliary inversion. Locative there, on the other hand, can occupy various syntactic positions in a sentence and does not undergo SAI. Second, existential there is not semantically transparent, whereas the meaning of locative there is clearly definable as a spatial adverbial. Third, a phonological distinction is apparent in that existential there is unstressed whereas locative there is stressed. Lastly, the here/there opposition appears to be non-existent in the case of existential there.

These features have become what are called the 'formal' arguments that are recurrently used in the literature to distinguish between the two theres in research that has, as a starting point, the assumption that the two theres are distinct (Birner 1996: 24-29; Birner \& Ward 1993; Breivik 1977: 342; Dorgeloh 1997: 20, 52).

\subsubsection{Unifying features}

As seen above, the two uses of there undeniably have features which differentiate them. However, there are also features that suggest a close relation between locative there and existential

\footnotetext{
${ }^{6}$ Locative there as defined by the Britannica World Language Dictionary: "in a place other than that of the speaker, opposed to here." (1961: 1302). Also in Thatcher (1971: 869) locative there is "often opposed to here, there generally denoting the place most distant."
} 
there. These similarities, which form the core arguments of the 'relatedness position,' are: the shared sign, and evidence at the syntactic, semantic, and phonological levels.

\subsubsection{Single graphic representation}

The first and most obvious unifying feature is that the two uses are semiologically identical, that is, they share a unique graphic representation: THERE. This shared linguistic sign is prime evidence that the two uses are somehow inherently linked, and any hypothesis of a distinction would need to address this observation. This, in fact, has been recognized by Breivik and Kimball:

To my knowledge, no plausible hypothesis has previously been advanced as to why the morpheme there - and not, say it came to be used in existential sentences. Kimball (1973: 262) writes: 'The difficulties with the rule of There-Insertion are, as with most known rules, insurmountable. It fails to explain why there is inserted and not, say, chop suey; or whether the there that is inserted is the same as the deictic there, or what relation the two bear to each other.' (Breivik 1981: 20)

The fact that no tenable hypothesis has been proposed to deal with the unicity of the sign remains true today.

At the phonological level, the distinction between the existential and locative there is not always so clear-cut as is often portrayed in the literature. Breivik chides those authors who make claims that existential there is always without stress and adds that "the spoken material of the Survey of English Usage contains 958 instances of existential there; 70 of these are pronounced like the locative there" (1977: 339). He also adds that the "overt phonological distinction between the two theres may $[\ldots]$ be absent."

\subsubsection{Syntactic similarities/similar discourse constructions}

Syntactically, both theres can be found in the same sentence-initial pre-verbal position indicating a possible relation between locative there and existential there. When locative there is in this position, it is said to play a role in what is called the locative inversion construction, as seen 
below in example (8). Existential there, restricted to this initial position, is considered the "dummy element" or "filler" for the existential there construction (example 9):

\section{LOCATIVE INVERSION :}

WITH THERE $E_{\mathbf{L}}$ : A probable twenty-five miles lay between him and the hut tenanted by Dot's friend. <There > lay < safety, for about the hut the land was free from grass, as to a greater extent it was free about the wells and tanks of Windee.>

[Upfield 1931: 204-token from Birner 1996: ex. 31b]

\section{(9) EXISTENTIAL THERE CONSTRUCIION:}

$<$ There $>$ was $<$ a person called Nana who ruled the nursery. $>$

[Bianco 1994: 15]

Even though some authors do not consider this as evidence of a connection between the two theres (Breivik 1981: 7), and others consider the two constructions as unique and distinct (Birner 1996: 23-29; Birner \& Ward 1993; Bresnan 1994; Dorgeloh 1997: 52), it has nonetheless consistently been shown from different theoretical perspectives that both are presentative constructions (Bolinger 1977: 93; Breivik 1981: 12, 1983: 366; Levin \& Rappaport Hovav 1995: 218-250). ${ }^{7}$ Furthermore, studies have consistently demonstrated that both constructions share a number of features and discourse functions which will be expounded on below.

The similarities between locative inversion and the existential there construction range from similar syntactic structure and shared agreement anomalies, to the types of verbs that appear in the constructions, to discourse functions such as information-packaging, connective and anchoring (Green 1980), to the information status of elements allowable in the pre-verbal and post-verbal NP.

\footnotetext{
${ }^{7}$ See also Allan 1971; Birner and Ward 1995, 1998; Bolinger 1977; Bresnan 1994; Celce-Murcia \& Larsen-Freeman 1999; Dorgeloh 1997; Erdmann 1976; Firbas 1964; Givón 1993; Hartvigson \& Jakobsen 1974; Huckin \& Hutz-Pesante 1988; Levin \& Rappaport-Hovav 1995; Penhallurick 1984; Sheintuch 1980; Sasaki 1999.
} 
Syntactically, inversion and the existential there construction are similar in that both have 'atypical' word orders; that is, they are not structured in canonical word order. More precisely, what is positioned as the post-verbal constituent in these constructions appears to be the 'logical' subject of the sentence, a constituent which would appear pre-verbally in canonical word order. In addition, the pre-verbal constituent of both constructions is not typical of canonical sentences; for locative inversion, generally it is a prepositional phrase, and for the existential construction, it is there sometimes preceded by a PP. (This analysis of the constructions is based on descriptive definitions used in the literature and is by no means a syntactic analysis which, as Birner states, "remains controversial" (1996: 12) due to the "mixed" evidence for subject status (Dorgeloh 1997: 36; see also Bresnan 1994)).

As stated above, the post-verbal constituent of both discourse constructions appears to be the logical subject of the sentence, and the reason for this affirmation is that the verb tends to agree with the post-verbal noun phrase (PVNP):

\section{(10) AGREEMENT IN INVERSION :}

$3^{\mathrm{RD}}$ PERSON SINGULAR : $<$ On the right of the drive $>$ was $<\underline{\text { a meadow }}$ of coarse grass. $>$

$3^{\text {RD }}$ PERSON PLURAL: < Further away> were < kitchen gardens and chicken runs.>

[Golding 1939: 35]

\section{(11) AGREEMENT IN EXISTENTIAL THERE CONSTRUCTION:}

$3^{\mathrm{RD}}$ PERSON SINGULAR. : There is one line that won't impress the girls.

$3^{\mathrm{RD}}$ PERSON PLURAL: There are 5 things you can do to take the smart risk: Look First. Wear the gear. Get trained. Drive sober. Buckle up.

[Advertisement of the Injury Prevention Foundation, 'The Stupid Line']

Even though subject-verb agreement with the PVNP is a common phenomenon with inversion and the existential there construction, lack of agreement has also been well attested in the literature, especially for the latter construction: 


\section{(12) LACK OF AGREEMENT IN INVERSION :}

a. <On the wall> is <two Winchester rifles, a Savage highpowered weapon, and a shotgun ....>

[ Upfield 1950a: 179, from Birner 1996 : 14, ex. 7]

b. <On the title page of this report of this "Grossaktion", as the Germans called it, > was inscribed in decorative Gothic lettering $<$ the words, there are no more Jewish dwellings in Warsaw.>

[=Hartvigson and Jacobsen 1974: 60, ex. 67]

\section{LACK OF AGREEMENT IN EXISTENTIAL THERE CONSTRUCTION:}

a. There was forty acres in bluegrass.

[Harry S. Truman, quoted in Merle Miller, Plain Speaking, 1973token from Merriam-Webster, 1989, p. 900]

b. But for every big, dumb move like this, there's half a dozen small, smart details.

[Example from a newspaper, token from Burchfield, R.W., The New Fowler's Modern English Usage, 1996, p. 778]

c. How many's there?

[token from personal communication, Mary Boudreau, 10/9/98 $]^{8}$

The agreement irregularity found in inversion has fueled "disagreement in the literature over the subject-hood of the post-posed item" (Birner 1996: 14; see also Bresnan 1994: 74; Dorgeloh 1997: 36-39). This comment, though intended within the context of a discussion on inversion, is equally applicable for existential there sentences. Indeed, Erdmann states that "research has so far failed adequately to determine the grammatical status of non-adverbial there" (1990) due to the same conflicting evidence for subject-hood.

\footnotetext{
8 "When there is a 'dummy' or anticipatory subject, the number of the verb is determined by the number of the true subject following. [...] That is the way things are supposed to work and often do, but there are complications. For instance, when a compound subject follows the verb and the first element is singular, we find mixed usage-the verb may be either singular or plural. Jesperson $1909-49$ (vol.2) explains the singular verb as a case of attraction of the verb to the first subject [...] Bryant 1962 cites studies that show the singular verb is much more common in standard English. [...] We also find mixed usage when a collective noun is [in PVNP] [...] Harder to explain, perhaps is the long-standing propensity for there is or there's in every case, even when the following subject is clearly plural and there are no complications to cloud our minds." (Webster's Dictionary of English Usage 1989: 899). See also Jespersen 1949: 107; Givón 1993: vol. II, 207; Celce-Murcia \& Larsen Freeman 1999: 448; Hannay 1985: 15-16; McCloskey 1991: 563; Burchfield 1996: 778; Fowler 1970: 633, 1996: 778; Breivik 1981: 15, 1983: 206; Sparks 1984: 182.
} 
An additional shared syntactic feature which conflicts with the analysis of the post-verbal constituent as subject is the felicitous appearance of non-nominative pronouns ${ }^{9}$ in that position. This occurs both with inversion and with existential there constructions:

\section{(14) INVERSION :}

Top: beside Beijing University's No Name Lake: <second from left $>$ is $<$ Fu the Enforcer $>$; $[\ldots]<$ sixth from left $>$ is $<\underline{\text { me. }}>$

[Wong 1996: 72]

\section{EXISTENTIAL THERE CONSTRUCTION:}

'Fill the instruments with gold!' and they fill the tuba with gold and they fill the trombone with gold and then there's me with the damn piccolo...

[www. Insultmonger.com/jokes/people_jokes_7.htm-19K]

This 'mixed' evidence of subject-hood with both of these non-canonical constructions suggests perhaps that these constructions have a structure of their own, which has certain things in common.

Syntactic similarities aside, there are also similarities in the types of verbs sanctioned within both constructions. The verbs typically occurring both in locative and existential there structures are verbs of existence or appearance, as evidenced in examples (16) and (17) below (Levin \& Rappaport Hovav 1995: 233): ${ }^{10}$

INVERSION:

VERB OF EXISTENCE : $<$ There at a table piled with papers $>$ sat $<$ the biggest man I'd ever seen in my life.>

VERB OF APPEARANCE: <There, peering up at me,> rose <the poking, snakelike, angry, fearless, eye-glittering head of a turtle.>

[Golden 1997: 59 and 79 respectively]

\footnotetext{
9 Birner (1996: 101) suggests that these pronouns perform a deictic function of 'pointing' to something which has not previously been mentioned which makes them compatible with the position of 'new' information.

${ }^{10}$ See also Firbas 1966: 243, Breivik 1981: 18, Erdmann 1976: 135-142, Penhallurick 1984, and Bresnan 1994.
} 
(17)

EXISTENTIAL THERE:

VERB OF EXISTENCE: <Somewhere between the various thoughts about my mother-somewhere past the discomfort in my lipsthere $>$ nestled $<$ a pleasant thought I tried again and again to bring into focus. $>$

[Golden 1997: 16]

VERB OF APPEARANCE : The front tube warmed; I could see its pinpoint glow behind the edge of the large dial. There came $<$ the familiar sharp buzzing sound; $>$ we smelled electricity, then heard static... a voice said, 'Pearl Harbor has been bombed...'

[Choy 1995: 191]

More recently, these verbs have been described as informationally light (Birner 1996: 115, 119; Bresnan 1994: 93-94; Levin \& Rappaport Hovav 1995: 220, 251) and as bringing in no discoursenew information (Birner 1994: 254; Birner 1996: 119; Levin \& Rappaport Hovav 1995: 233). Levin and Rappaport Hovav even explicitly state that the class of verbs found in inversion is interestingly similar to those found in there-insertion constructions and that the solution to the distributional variety of verbs found in inversion "can be extended to [...] there-insertion" (1995: 220). Thus although they found that the types of verbs found in inversion and the existential there construction do not all inherently express existence or appearance, they discovered that "aspects of the meaning of these verbs are de-emphasized when they are found in these constructions" so that in these contexts they in fact play the role of verbs of existence or appearance (Levin \& Rappaport Hovav 1995: 258; see also Birner 1996: 119; Dorgeloh 1997: 88):

(18)

INVERSION:

NOT INHERENTLY A VERB OF EXISTENCE : <Over a Bunsen Burner> bubbled $<$ a big, earthenware dish of stew. $>$

[L'Engle 1962:39 from Birner 1996: 114, ex. 17]

EXISTENTIAL THERE:

NOT INHERENTLY A VERB OF EXISTENCE : $<$ In a dark corner there> fidgeted $<$ a nervous young girl. $>$

Here bubbling and fidgeting are typical behaviors of a cooking dish of stew and a nervous girl and so are inferable from the context, serving essentially to merely indicate the presence of the entity denoted by the post-verbal NP. 
Similarities between locative inversion and the existential there construction have also been identified at the discourse level. For one, both have been described as presentative constructions whereby "a scene is set [via the clause-initial constituent] and a referent is introduced on the scene to become the new focus of attention" (Levin \& Rappaport Hovav 1995:229; see also Dorgeloh 1997: 88). Some recent discussions describe the function of these constructions more in terms of information-packaging (Birner 1994, 1996; Birner \& Ward 1993). That is, these discourse constructions place relatively familiar information in clause-initial position, providing a link to the prior context for the relatively unfamiliar information that is packaged post-verbally. (Birner 1992: iii; see also Birner \& Ward 1993). This information-packaging function relates to the observation that there is a tendency in English, and in many other languages, "to order 'given' information before 'new' information in an utterance" (Birner \& Ward 1998: 9). This relative ordering of information presupposes a "connective component" in these constructions whereby 'new' information is linked to prior discourse via the pre-verbal 'given' information (Dorgeloh 1997: 48; Birner 1992: 110).

This connective component has also been ascribed to existential there constructions. Indeed, Sasaki's study of existential there sentences (1991) concludes that the PVNP (logical subjects) "tended to introduce a subtopic of a broader discourse topic as relatively new information [...] linking the subtopic to the preceding part of the discourse." In a similar vein, Bolinger describes the pre-verbal existential there as a stage which is a link to what has gone before, a link to the prior context (1983: 110).

At the level of discourse, a final similarity has to do with the actual information status of the constituents within the constructions. Birner notes that the post-verbal NP in locative inversion is not always discourse-new, which suggests that there are different degrees of familiarity (or newness) which cannot be adequately explained by the given/new dichotomy (Birner 1994: 242; see also Birner \& Ward 1993; Prince 1992). She proposes a cross-cutting matrix of four types of familiarity to distinguish the varying types of pre-verbal and post-verbal 'newness': DISCOURSEOLD/ DISCOURSE NEW and HEARER-OLD/HEARER NEW. According to these criteria, Birner concludes that locative inversion and existential there constructions are functionally different since the PVNP in locative inversion is constrained to be DISCOURSE-NEW whereas in existential there constructions 
it must be HEARER-NEW. Nevertheless, Birner concludes with a general characterization of inversion which subsumes both locative inversion and the existential there construction: the postverbal NP in an inversion "must always be less familiar than the information represented by the NP in the pre-verbal constituent" (Levin \& Rappaport Hovav 1995: 230). In other words, locative inversion links "relatively unfamiliar information" to "relatively familiar" information in the prior context [my emphasis] (Birner 1992: iii; Birner 1994: 255) as does the existential there construction.

In brief, what has been demonstrated here at the syntactic level is that both existential and locative there have a presentational function when used in inversion structures, as well as similar syntactic, verbal and discourse features.

\subsubsection{Semantic similarities}

A third level of evidence for similarities between existential and locative there lies in semantics. In section (2.2.2.1), it is mentioned that it is hard to attribute any referential meaning to existential there. Milsark, who calls existential there "semantically empty," nevertheless adds that existential there sentences "are consistently interpreted as existence statements in some sense in which other sentences are not [...and ] that it makes some sense to say that there means something" Milsark 1974: 25-26). ${ }^{11}$ This same notion of 'existence' is also found with certain uses of there which appear to have the properties of the locative use:

(20) The chance was there for the taking, but we made a hash of it. [=Hannay 1985: 13, ex. 44]

\footnotetext{
11 "Milsark's attempt to show that the relationship between [there ${ }_{\mathbf{E}}$ ] and existentiality does in fact provide a useful characterization of the meaning of the there ${ }_{E}$ constructions" (Breivik 1983: 4).
} 
(21) I really encouraged them but the will just wasn't there. [=Hannay 1985: 13, ex. 45]

(22) If the technology is there, someone will use it, si la technologie existe, quelqu'un l'ultilisera. [Robert \& Collins Senior French/English, English/French Dictionary 1994: 839, ex. c] ${ }^{12}$

Erdmann, who calls this use "predicative there" (1990: 55; 1976: 77), recognizes that it has lost some of its locative meaning and could be paraphrased as meaning 'be present' or 'be available'. Hannay also recognizes this and adds:

"Actually it might be tempting, [...] to regard there not as a weakened locative predicate but rather related to an existential, instantiative predicate. It is striking in this respect that there is little difference in meaning between sentences as the following:

a.) We hung on and on, but the opportunity simply was not there.

b.) We hung on and on, but there simply wasn't the opportunity." [Hannay 1985: 14]

Here, locative there produces a sense that is somewhat related in meaning to existential there which, in turn, hints at some kind of semantic connection between the two theres.

Essentially, what has been shown here is that existential and locative there share a certain overlap in the kind of meaning they can be used to express, the notion of 'existence.' The examples above are especially interesting from the theoretical perspective that underlies this study (the Guillaumian theory) which views word meaning as having an underlying dynamic potential that can produce various actualizations of meaning to serve the purposes of discourse functions and contextual needs.

\footnotetext{
${ }^{12}$ Bolinger (1977: 96) also comments on this same existential sense for the locative there and gives the following example, "The kind of cooperation we needed just wasn't there. (wasn't to be had, wasn't in existence)."
} 


\subsubsection{The neglect of locative there}

If one considers the enormous amount of discussion that has been generated by existential there, it is rather surprising that the problem of there is still at an impasse. However, by taking a step back, so to say, to view discussions from a wider perspective, a reason for this stand-off becomes apparent: studies have essentially overlooked locative there.

On the one hand, research that assumes there is a fundamental difference between the two theres uses the formal arguments for a distinction (section 2.2.1) to set locative there aside from discussion which, in turn, focuses almost exclusively on existential there (c.f. Breivik 1977: 342; Sasaki 1991). It is also assumed that locative there in pre-verbal position is of concern only because of the potential for ambiguity in that position, where a there could be interpreted as locative or existential. As a result, locative there in other syntactic positions tends to be disregarded in analysis, since it is considered unambiguously locative (Breivik 1983a).

Similarly, discussions of non-canonical constructions set the existential there construction aside to focus on inversion structures in which locative there is but a minor player (c.f. Dorgeloh 1997: \#52). In these cases, the distinction established between the existential there construction and inversion has the effect of masking any similarities which both constructions may have.

For those authors who hold that both theres are inherently the same word, the approach has generally been to use existential there as a model and to ascertain how locative there conforms to its use. This approach unwittingly disregards, first, cases of locative there which do not hint at a relationship between the two uses and second, the possibility that locative there could serve as a model to which existential there conforms. Nevertheless, some authors recognize a non-sentenceinitial locative there which has curious shifts in meaning expressing 'presence' or 'existence,' such as (21) above. Yet, even though this use is acknowledged, these studies offer no explanation as to how locative there can produce such an expressive effect. As such, locative there receives a slight nod of recognition but no in-depth analysis (c.f. Erdmann 1990). 
Therefore, considering all the research that has been expended on existential there, by comparison little is known about how locative there functions and the reasons it can express meaning variations that evoke interpretations of 'presence' or 'existence.' If existential there and locative there are two exploitations of the same meaning potential, then perhaps the parameters of research have been far too limited, focussed almost entirely on one actualization (existential there) of a word with a multi-faceted potential.

\subsubsection{Conclusion}

The problem that has been presented here is essentially a simple one: are existential there and locative there two uses of the same potential meaning, or two separate words coincidentally sharing a number of features at the lexical, syntactic and semantic levels? Two positions exist with respect to this question: one which views existential there and locative there as distinct words but which happen to share the same sign, and the second which views the two theres as polysemic variations of a single word. Both positions derive their core arguments from the features of the two uses. On the one hand, the syntactic, semantic, and phonological differences provide arguments for a 'distinction position.' On the other hand, the single graphic representation, THERE, shared by the two distinct uses, is a stalwart piece of evidence for the 'relatedness position,' to which can be added the syntactic and discourse level evidence, as well as evidence at the semantic level.

For either position, there are major questions which need to be addressed. For the position which holds that existential there and locative there are distinct theres, the major problem is to explain why they are semiologically identical, and by the same token, why they share the same syntactic space (see section 1.2.2.1) and discourse level features. For a unified account of there, there are two major hurdles. The first is to explain why existential there can undergo SAI whereas locative there cannot, and second, the role of stress needs to be determined.

At this point, if a tally of the distinguishing and unifying features presented in this chapter were done, the results would definitely favor a unified account of there. However, the questions that remain to be solved make THERE both a formidable challenge and a fascinating object of study. 


\section{CHAPTER 3}

\section{THEORETICAL FRAMEWORK}

\subsection{The Theory}

This research project will be done within the Guillaumian linguistic framework, a theory named after its founder, the French linguist Gustave Guillaume, and otherwise known as the Psychomechanics of Language. The essence of Guillaumian theory has been concisely stated in the following formula: it is "a word-based, meaning-focused theory which postulates a stable relationship between a sign and its meaning" (Enns 1994: vii). Since this theory focuses on meaning, its fundamental postulates are directly meaning-related. One basic postulate posits two levels of language on which meaning exists, the level of discourse where meaning is actualized and the level of tongue where meaning exists as a potential. A second postulate sees meaning as part and parcel of a dynamic underlying operational system. Finally, it is assumed that meaning plays an essential role in conditioning syntax, the latter being viewed as "not autonomous but conditioned by, among other things, the lexical and grammatical meanings of the words that go together to make up a sentence" (Duffley 1992: 6). These are three of the basic tenets of Guillaumian theory which will be expounded more thoroughly below and which provide the framework upon which this study is based.

As mentioned, two states of existence are postulated for language, which correspond to either POTENTIAL or ACTUAL meaning. DISCOURSE is the level where actual acts of speech exist and where meaning is ACTUALIZED. That is to say, of the varied senses ${ }^{13}$ a given word or morpheme can

\footnotetext{
13 "Sense" is a Guillaumian term used for meaning on the level of "discourse" as the product of actual speech acts.
} 
express, only a particular aspect of its MEANING POTENTIAL is utilized and therefore 'actualized' for a given speech act. In sum, this means that a word can yield different 'actualized' meanings on the level of discourse but that only one actualized meaning can be expressed at a given time for a particular speech act. The primary level at which meaning exists is the underlying level of TONGUE. This is the hidden mental construct of language wherein reside the POTENTIAL MEANINGS of all words and morphemes. POTENTIAL MEANING is the "permanent meaning-capacity which a word or morpheme possesses before it is utilized in any particular situation" (Duffley 1992: 15). Therefore, 'potential meaning' is made up of not-yet-exploited possibilities of meaning, whereas 'actualized meaning' is the realization of a specific aspect of potential meaning in an act of speech. In the case examined in this study, there is considered to have a potential meaning that allows it to be actualized in speech acts as locative or existential there.

Thus far, two levels of language have been established-one where meaning is perceivable and actualized and another where it is non-perceivable and potential. It is potential meaning (on the level of tongue), with its capacity for producing different effects (on the level of discourse), that forms what is known in Guillaumian theory as a "dynamic underlying operational system." Since the potential meaning of a word is seen as a capacity for different meaning possibilities of that word, that implies mental operations, however slight and imperceptible, whereby for a given situation only a specific sense of the potential is applied and hence expressed in a particular act of speech. These underlying mental operations reflect the operative nature of potential meaning and hence, the existence of an operative system.

These underlying mental operations also reflect the dynamic nature of potential meaning which is key to understanding and differentiating the Guillaumian theory of meaning from other semantic theories. Perhaps what best illustrates the dynamic nature of potential meaning is the simple everyday rubber band. A rubber band has the potential to expand and stretch to varying degrees as needed, yet it retains its basic rubber-bandish characteristics in all conditions. It is dynamic by nature. In contrast to this, a building block lacks this operational potential. If it is a oneinch block, it remains so and could be described as static in nature. For the block, it would be rather easy to come up with a list of all of its characteristics, but to describe the rubber band with all its 
potential would necessarily mean recognizing its dynamic character. Meaning, too, can be viewed either as a static or a dynamic entity.

By analogy, many semantic theories ${ }^{14}$ view meaning as a static entity similar to the building block. Word meanings are represented by listing features and/or functions ${ }^{15}$ common to all uses of a given word or by searching for a core meaning. ${ }^{16}$ Guillaumian theory, on the other hand, sees meaning with an inherently dynamic nature. Meaning has a potential that can stretch, so to say, to varying degrees. It is this dynamic nature of potential meaning that gives rise to meaning possibilities which in turn form the operational system. This dynamic nature, however, is not ad hoc but rather reflects one of the basic human capacities of human thought: the ability to generalize and to particularize. Therefore, the meaning extensions found within the operational system tend to extend from particular to more generalized meanings. It should be evident that viewing meaning with a potential, dynamic nature as opposed to a static one may help shed new light in the area of semantics and help solve certain mysteries of word usage.

A last important theoretical consideration is the relationship between meaning and syntax. Syntax has long been considered autonomous from meaning in many linguistic theories, be they semantic or syntactic. ${ }^{17}$ However, from the psychomechanical perspective, syntax should not be considered autonomous because it is, in fact, conditioned partially by meaning. Were it not for word meanings, there would be no limit to the syntactic relationships words could enter into. Indeed, it is meaning that determines whether words can enter into certain syntactic relationships and not into others. This is an interesting insight because it allows one to look at meaning not only from the

\footnotetext{
14 This study explores the assumption that posits two theres which is typical of TG-type analyses. As a result, the theoretical focus here is not on Cognitive Linguistics but on those theories which propose a static definition of meaning as a opposed to a dynamic one.

${ }^{15}$ See Jackendoff (1992), whose conceptual semantics is based on features and functions.

${ }^{16}$ The term core is used in Levin and Pinker (1992: 3): "...the core content of semantic representations is beginning to be identified..."

${ }^{17}$ Jackendoff (1992: 43) "The conceptual features and functions proposed here are indifferent to how they are expressed syntactically..." See also Ellis (1993: 110) “..the field [of linguistics] is dominated by a theory [Generative] that still tries to hold grammar separate from semantics..."
} 
perspective of 'pure' meaning but also from the perspective of syntax and its relationship with meaning. In the case of the present study, it will be shown not only that some meaning actualizations of there can be expressed only through specific syntactic constructions, but that a change in the meaning actualization of there in the same syntactic structure will trigger necessary phonological changes used to distinguish the two actualizations.

These, then, are the essentials of the Guillaumian theory of linguistics, where meaning is seen as existing on two levels of language, either in discourse or on the underlying level of tongue, and actual meanings are partial realizations of an underlying potential meaning, the latter being viewed as a dynamic system as opposed to a static entity. This theory provides a unique and ideal framework for dealing with multiple uses of a single form and thus offers a viable means of dealing with the two uses of there, which, due to syntactic, semantic and phonological differences, are considered by many linguists and grammarians as different words. Through the study of the two functions of there and their contextual meanings, the aim will be to determine whether there is a unifying factor that corresponds to the two uses, and thus attempt the reconstruction of the potential meaning of there.

\subsection{The hypothesis}

In the literature, there lingers the linguistic intuition that existential there may be an extension of locative there (Celce-Murcia \& Larsen-Freeman 1999 450; Dorgeloh 1997: 20; Huffman 1999). It is this same intuition that is the driving force behind this thesis. It is proposed here that there is indeed one underlying potential meaning for both uses of THERE: it is 'pure space' without reference to the speaker, and it stands in opposition to HERE, which evokes space that is speaker-centered.

Furthermore, it is assumed that there are several features which are intimately tied to the actualization process of this potential meaning:

1. ASSOCIATIVE POTENTIAL- (Wiese 1983: 373) this is the inherent capacity of there to form associations with linguistic or pragmatic referents or between constituents at the 
discourse level, which allows for the construction of a space wherein events and entities or discourse information can be situated. The term 'associative potential' is used because it is less limiting than what is commonly known as "referring" which would subsume only some of the uses of locative there. (see sections 3.4 and 4.1 )

2. MEANING ACTUALIZATIONS - these are the various senses that can be actualized in spoken or written discourse.

3. STRESS - is systematically used as a discourse level marker indicating various types of focus on the meaning of there. (see section 4.2)

4. LEXICAL-SYNTACTIC RELATIONSHIPS-it is assumed that the syntactic relationships there entertains reflect both its meaning and associative potential. Thus the participation of existential there in both SAI and the structure of inversion should be explainable in terms of meaning and an associative potential.

\subsection{Methodology}

This study was based on a corpus of 826 naturally-occurring tokens collected from a variety of sources: periodicals, novels, biographies, advertising, and some spoken sources, such as television and personal conversations. The corpus was divided into four sub-sections: locative there (193 tokens), existential there (324 tokens), inversion (102 tokens), and a section for tokens with here (205). Since the words there, here and the inversion construction depend on context for their felicitous interpretation, sufficient context was included with the tokens so that either a referent was available or the overall tone of the passage was evident. The tokens were collected both randomly, whenever I came across them in readings, and also non-randomly; that is tokens appearing in the first 100 pages of three books were all collected, as well as all the tokens from several catalogues, to give a more complete idea of the possibilities of usage. The tokens were analyzed according to following criteria: 
1. Type of reference with locative there, i.e. anaphoric, cataphoric, pragmatic, situational, etc.

2. Identity of referent of locative there and here

3. Presence or absence of stress

4. Patterns of word-order or discourse construction

5. Verb agreement with the post-verbal constituent

Electronic corpora (London-Lund and British National) were used on a few occasions to verify some linguistic intuitions. Also used were some informant-reaction tests that were given to native English speakers to determine the meaning and the intonational realization of certain troublesome occurrences of locative there.

Based on observations of locative there and the referring process, a model was designed to reflect the ASSOCIATIVE PROCESS which covers a broader spectrum of associations than does the term 'referring.' This model provided a template which then made it possible to see the associations that there entertained at the discourse level with the existential use and thereby the functional similarities of the locative and existential use of there.

\subsection{Model of the Associative Potential}

\subsubsection{The underlying dynamics of space}

In order to understand the model (based on how there functions referentially), it is helpful to look at how space is conceived with reference to the 'real world.' This is especially true since, at first glance, little appears to be said about the meaning of locative there: it is 'space' which is outside of here and distant as opposed to close. However, from a referential (or real-life) perspective much more can be said about 'space'; it can be given various limits in size and it offers a potential place where 'things' can be situated. 
From a referential point of view, 'space' is undefined until boundaries are set, be they concrete or abstract. For example, space can be defined in terms of the boundaries of a cardboard box, a car, a city, to the RAM space available in a computer system for temporary information storage. So, space tends to be defined by various limits, whether concrete or abstract. Once a space is defined, it has a potential for use. For example, only when a counter top is constructed does it provide a place where things can be 'situated.'

Another notion that is relevant to space is that there is a correspondence between the space and the items situated within it. That is, 'space' will be defined according to the contents to be situated, and similarly, the items situated have to fit the 'container.' For instance, the box which contains a diamond ring will be constructed smaller than that for a computer, and similarly, a diamond ring will not be placed in a computer box nor vice versa. In essence, containers correspond to the items contained.

In conclusion, there are three features which characterize referential space: (1) space needs to be defined for use, (2) space is used to situate things, and (3) there is a correspondence between the constructed space and the situated items. Once space is defined, it provides a place wherein events or entities which correspond to this 'container-space' can be placed or situated.

\subsubsection{Description of the Associative Process}

The above description of the use of space in 'real life' actually corresponds in many respects to the way locative there functions associatively. Indeed, the space offered by there (see figure 1) needs to be defined for use (figure 2), and, once defined, serves as a situator for entities and events and (figures 3 and 4) corresponds to the 'items' situated in it.

At its basic functional capacity, locative there offers a user its spatial meaning. Undefined by a linguistic or situational context, the space provided by locative there is an open space that is only minimally defined as not containing the speaker: 
Figure 1

Non-constructed Open Space

(23) There, Mel lived with an uncle and aunt. (The exact space of there
is undefined.)

there

The space evoked by there can be involved in what is commonly called the referring process. According to Halliday, the referring process sets up a "semantic relationship" between a referring expression and a referent which is available in the universe of discourse (1985: 295-296). ${ }^{18}$ And indeed, the meaning of locative there allows it to match up (or associate) with a linguistic or situational referent that is semantically related. In example (24) below, the spatial meaning of there allows it to associate with Paris, a place, and not with $\mathrm{Mel}$, a person:

Figure 2

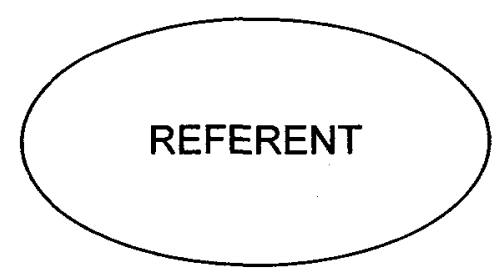

\section{Association with a Referent}

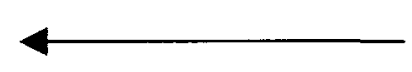

(24) Mel went to Paris when he was 12 years of age. There, he lived for 20 years.

This step has been defined here as an ASSOCIATION which comes from the inherent “associative potential" (Wiese 1983: 373) of there. The term "associative potential," used by Wiese for pronouns, more accurately describes the inherent nature of there, as opposed to just a semantic relationship. This is because there can, in fact, associate with more than one constituent, as well as with constituents that are not 'purely' spatial, but are, for example, temporal elements or more abstract notions of world knowledge, as will be seen a bit later.

\footnotetext{
${ }^{18}$ The universe of discourse implies different modes of referencing-linguistic, pragmatic, situational, and discourse. This means, more precisely, that a referent may be (1) available in the linguistic context, (2) pragmatically reconstructed, (3) situationally available, and (4), as will be shown later, discourse-related.
} 
Once an association has been established, the associative process does not stop; the referent expression(s) also plays a role. The referent expression(s), through its meaning, sets the boundaries or shapes the previously open space of there:

Figure 3 Reconfiguration of Container-Space to Referent
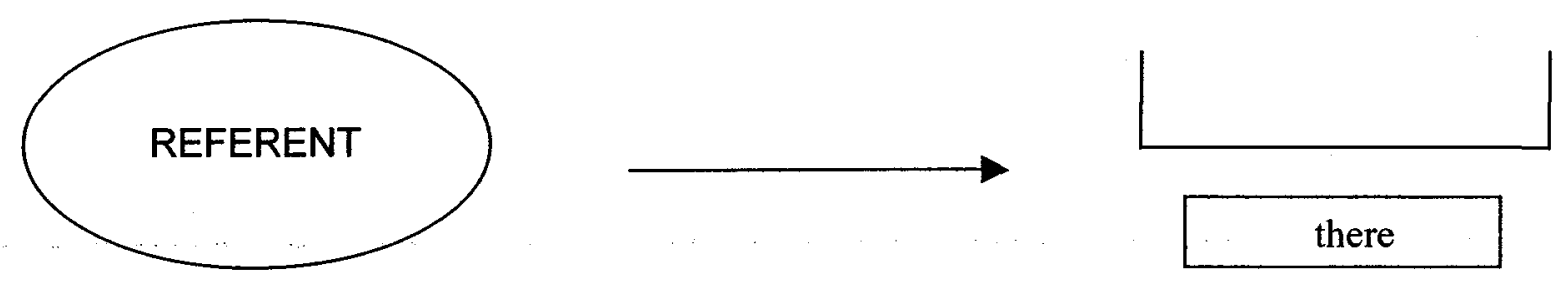

(25) a. Mel went to Paris when he was 12 years of age. There, $\therefore$

b. Mel went to the corner store. There, ...

Here, the spaces represented by there in (25a) and (25b) are sized differently since the boundaries have been shaped by the different referents, Paris and the corner store. This shows why referring expressions, such as pronouns, and the adverbs there and here, are commonly considered CONTEXT DEPENDENT forms, since they work together with other constituents that are linguistically, pragmatically or situationally available.

At this point, the referring process has resulted in what can be called a SPATIAL CONSTRUCTION which has been shaped by the context. This "(re)constructed" (Bosch 1987) or reconfigured space is basically a CONTAINER-SPACE: it provides a place wherein ENTITIES or EVENTS can be situated. 
Figure 4

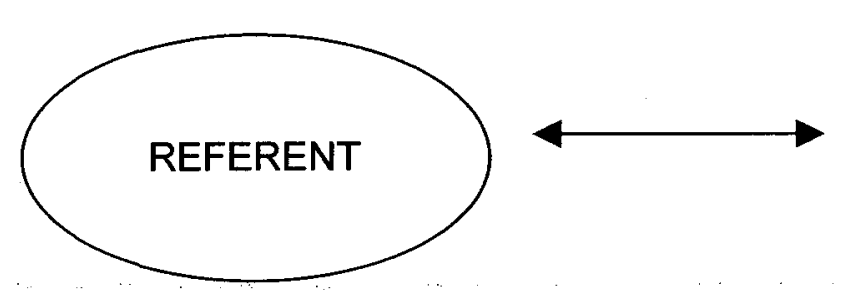

Connection to an Entity or an Event

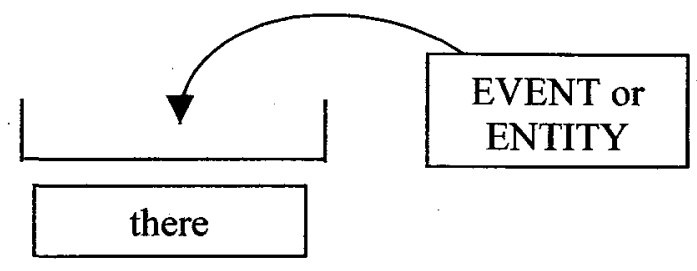

(26) a. Mel went to $\underline{\text { Paris }}$ when he was 12 years of age. Mel lived with his uncle and aunt.

b. Mel went to $\underline{\text { Paris }}$ when he was 12 years of age. There, Mel lived with his uncle and aunt.

The two examples in (26) above have been given to illustrate how there connects an event to a (re)constructed space. In both examples, there are two events, Mel went to Paris and Mel lived with an uncle and aunt. However, in (26a) one can only infer that Mel lived with his uncle and aunt in Paris. On the other hand, in (26b), the event Mel lived with his uncle and aunt is clearly linked to Paris by means of there which referentially reconfigures a space: Paris. Locative there thus provides a linguistic means to LINK an event to a previously given space, which is reconfigured by the associative process. This demonstrates that there has an inherent CONNECTIVE CAPACITY.

In brief, the associative process underlying the locative use of there is a dynamic process which is represented in the "Model of the Associative Potential of There" (following page). Essentially, three operations are involved: the non-constructed open space (figure \#1) associates first with the referent expression(s) available in the universe of discourse (figure \#2); second, the referent expression(s) reconfigures the container-space of there (figure \#3); and thirdly, an entity or event is situated within the container-space (figure \#4). 
Figure 5 : MODEL OF THE ASSOCIATIVE POTENTIAL OF THERE

1 Non-constructed Open Space

(applies to anaphoric, cataphoric, pragmatic or situational associations)

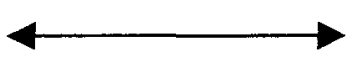

there

\section{Association with a Referent}
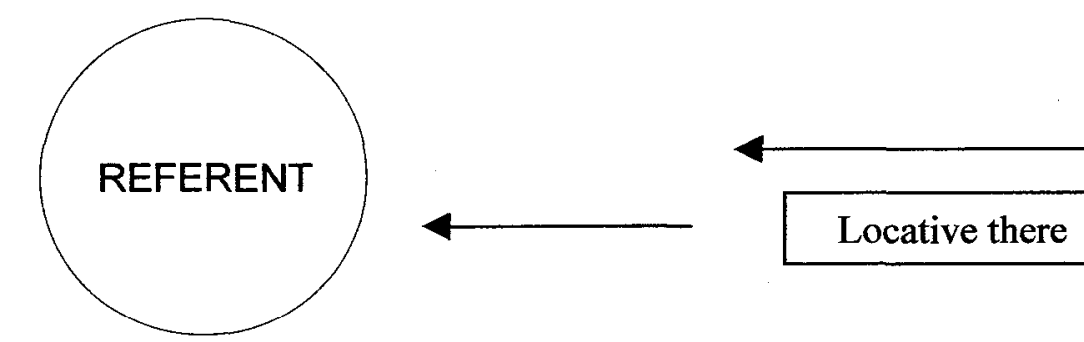

3 Reconfiguration of Container Space to Referent

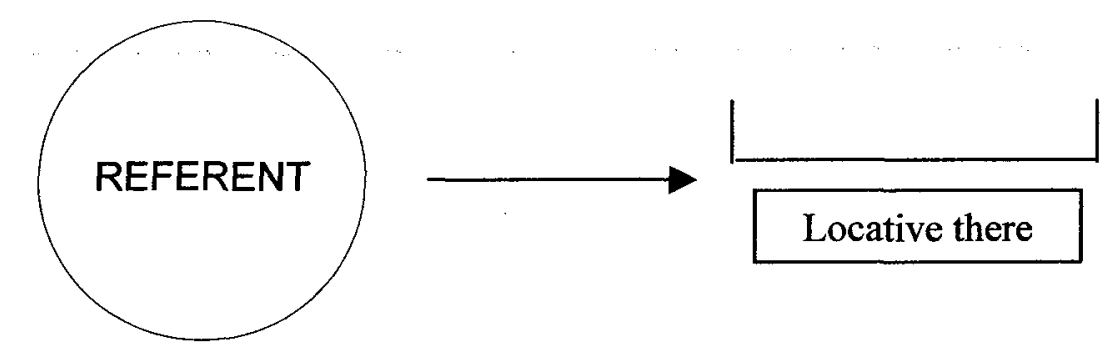

\section{Connection to an Entity or an Event}

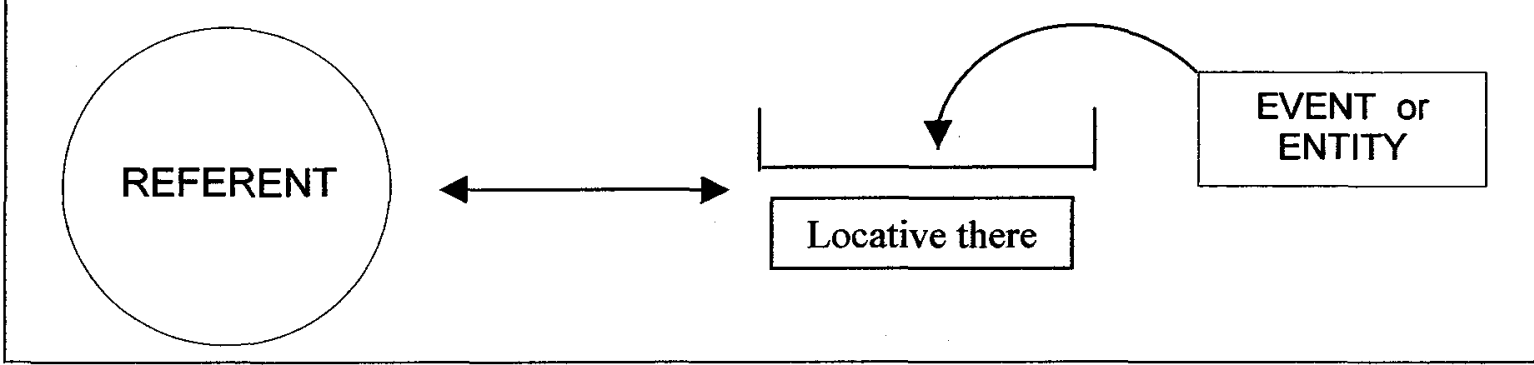




\section{CHAPTER 4}

\section{DISCUSSION}

It has been pointed out in Chapter 2 that locative there has been largely ignored in the literature, creating an unfortunate knowledge gap in the study of there. Thus the primary focus of this chapter will be on locative there. The first section deals with the theoretical assumption of the substitutability of there, which will be shown to have hindered understanding of the 'locative' use of there. It will be demonstrated rather that locative there functions associatively. The second section explores the role of stress and its relationship to meaning in the different actualizations of there. Finally, discussion will center on the semantics of there in order to understand how locative uses of there can evoke meanings of existence.

\subsection{The Associative Function of there}

\subsubsection{The inadequacy of substitution to explain the function of locative there}

In the literature, locative there is considered a pro-form, a label that brings it under the umbrella of pronominal items and suggests that it functions by substitution. Many authors who have focused on pronominal issues, however, recognize the inadequacy of the notion of substitution to describe pro-form phenomena (Bosch 1987: 70; Hausser 1979: 109; Wiese 1983:373). As Quirk et al. put it:

Pronoun is a misnomer $[\ldots]$ the relationship which often obtains between a pronoun and its ANTECEDENT [...] is not one which can be explained by the simple act of replacement. (Quirk et al. 1985: 76) 
Criticism of substitution was primarily directed at early transformational approaches which focussed on intra-sentential substitution whereby "pronouns were surface-structure substitutes for underlying full NP" (Wiese 1983:376; see also Bosch 1983: 23-26). As the following example demonstrates, many pronoun associations occur beyond sentence boundaries:

(27) $[\ldots]$ while we were traveling, Céleste and I became engaged. If I become your King, she will be your Queen.

[Brunhoff 1933: 9]

Additionally, criticism was based on cases when there is no linguistic antecedent for a pronoun and yet a referential association is understood through the situational context. The following example illustrates this well; the pronoun 'it' clearly associates with 'table' even though there is no prior mention of the word denoting this object:

(28) SITUATIONAL CONTEXT: A man is watching another man trying to put a large table into his car.

COMMENT BY THE MAN WATCHING: "You'll never manage to put it in there."

[=Bosch 1987: 70]

Another example which shows the limitations of substitution are the "cases where the overt antecedent is of a syntactic category that could not possibly determine the gender and number of an anaphoric pronoun" (Bosch 1987:70):

(29) Shakespearean imitators don't usually capture his style.

Here, the antecedent that allows for the interpretation of 'his' is not a noun but the adjective 'Shakespearean,' and therefore interpretation cannot be explained in terms of substitution.

Unfortunately, the notion of substitution permeates the literature dealing with there. It is used not only to describe locative there (30), but as an additional argument to distinguish locative there from existential there (31): 
(30) a. In (13), [locative there] functions as a pro-form for the phrase on the table. (Breivik 1977: 336)

b. [locative there] is a pro-form for a locative phrase (Allan 1971:

5)

(31) a. First because the [existential there] is not a locative constituent, i.e., it is not 'a copy or anticipation of adverbials of place, direction etc.' (Erdmann 1990: 60 in Dorgeloh 1997: 52)

b. [existential there is not] simply locative inversion with there standing in as a pro-form for the locative. (Birner 1996: 24)

c. [existential there] does not substitute for a locative adverbial. (Breivik 1983: 156)

Nowhere is the assumption of substitution questioned as inappropriate to describe the referential associations locative there entertains. Yet, similar to pronouns, locative there functions beyond sentence borders:

(32) “The Japs are fighting in Hong Kong now. Mr. O'Connor's son is there with the Commonwealth troops."

[Choy 1995: 226]

Moreover, it can form pragmatic associations that are not restricted to linguistic boundaries. In example (33) below, for instance, locative there is not a substitute for any prior linguistic antecedent since the word there is part of a title. Nevertheless, locative there is associated to the picture beside it and to pragmatic inferences in which the existence of other beings in the universe is questioned. Furthermore, example (28) shows that locative there can refer directly to something in the situational context.

"IS ANYONE OUT THERE?"

TEXTUAL CONTEXT: Section title of a children's book, located next to a picture of a star-filled sky.

[Funston 1996: 46]

It can be concluded that locative there functions not by substitution but by a process that allows it to form associations with linguistically, situationally or pragmatically constructed 
referents. This conclusion has the effect of discrediting the argument of substitution that is used to distinguish locative there from existential there. More precisely, if existential there "is not a locative constituent [because] it is not a copy or anticipation of adverbials of place"19 (Dorgeloh 1997: 24; Erdmann 1990: 60), then by using the same argument, neither can locative there in (33) and (28) above be considered a locative constituent because in these cases it is not a copy of an adverbial of place. Locative there of course does function as a spatial constituent. What is suggested here is that inspection of locative there must recognize its functional capacity as a referring expression rather than as a substitute.

Even though locative there can be considered a referring expression, after analysis of the corpus, it was recognized that the term 'referring' was inadequate to describe the associations which locative there entertains. As a result, the terms 'association' and 'associative potential' were felt to more suitably express the functional capacity of there.

\subsubsection{Various types of associations}

The purpose of this section is to demonstrate the way locative there functions by association, and how, in turn, these associations validate the associative model proposed for there. The analysis is predicated on the postulate that meaning is fundamental to the associative process. The constituents involved provide meaning to configure a space that fits the needs of the context. Not only does locative there supply its meaning as a foundation for a spatial construction but so do other words designating the containing space and the items contained within it.

\subsubsection{1 'Classic' anaphoric associations with spatial referents}

'Classic' cases of spatial referencing provide a good starting point to evaluate the way locative there functions. The term 'classic' is used because the in-text anaphoric referents are

\footnotetext{
${ }^{19}$ This argument was directed against the early locative analyses of Kuno (1971), Lyons (1967), and Sampson (1972).
} 
clearly locative, and the identification of the referents poses no problems. The following are two examples of 'classic' anaphoric associations:

(34) Yet a land that is entirely linear is itself limited, and the sorrow of a place like California, it often seems, is that no one there knows who he will be (or who he will be with) a year from now.

[Iyer, P. "Springtime, here we come," Time, 01/04/96, p. 72]

(35) [...] to see if Kazuo would be able to meet Meiying by the bench under the trees. There, Meiying would tell me what Kazuo had said to her $[\ldots]$

[Choy 1995: 218]

These examples clearly reflect an associative process. In example (34), locative there semantically associates with the referent expression, California, which reconfigures the minimal representation of space corresponding to there to provide a container-space in which is contained no one. In example (35), the fronted locative there semantically associates with the anaphoric referent expression by the bench under the trees. The reconfiguration of a space provides a place wherein is situated the event, Meiying would talk to me [...].

In both cases, the locative referent is 'given' information. Locative there provides the means of tying back into that specific locative information by means of a flexibly configurable containerspace. That space then allows an entity, in example (34), and an event, in example (35), to be linked to a given place, a link which otherwise would have to be inferred. These cases of 'pure' locative construction are common enough, and they easily confirm the associative model proposed in the hypothesis (section 3.3). The challenge, though, is that the model must be able to reflect the other locative uses of there.

\subsubsection{Temporal associations: the construction of temporal space}

It is a well recognized fact that locative there can function in the temporal domain. However, no thorough explanation has ever been provided for how this occurs. The process and the conditions that provide locative there with a temporal sense will be discussed in this section. This analysis of 
the temporal spatial construction will show just how essential meaning is to the associative process; moreover, it will again validate the associative model of there.

Since locative there is a context dependent form, it associates and works with what is retrievable in the universe of discourse. Moreover, since it is semantically locative, it is normal that it should associate with other locative elements. As a result, one might postulate that a necessary condition for a temporal reconfiguration be the absence of a spatial referent in the nearby context (as in example (38) below). However, the following example demonstrates that this is not a necessary condition.

(36) When two children from the remote village of Mayibout, in Gabon, discovered a dead chimpanzee lying in the undergrowth near their home a few weeks ago, they were delighted. Bush meat is a delicacy throughout the rain forests of central Africa, and chimps are particularly prized for their size and scarcity. Villagers helped carry the primate back to Mayibout, where it was skinned, cooked and eaten. There the festivities ended. Within a week, nearly all those who had prepared the animal for the pot had fallen ill with a high fever. Some began bleeding from the eyes and mouth. By last week thirteen were dead. (my emphasis)

[Purvis, A., "Where does Ebola hide." Time, 04/03/96]

Here, the village of Mayibout provides a nearby potential locative referent with which locative there could associate. However, there does not associate with Mayibout, but rather denotes a temporal space which could be paraphrased 'at that point in time' or 'then.' This suggests that there are other factors that have overridden this locative association. It is interesting to note that point in the expression at that point in time is primarily a spatial concept that is being applied to time.

One possible factor that could explain the temporal reading of locative there is that the preceding constituents are events that are sequenced in time. That is, the prized chimpanzee meat was first skinned, then cooked, then eaten. Locative there does indeed associate with these elements and the moment in time up to which they lead, so as to construct an abstract temporal containerspace corresponding to 'at that point in time' or 'then.' However, the following modification of the post-there passage shows that it is not only the referent expression that conditions the type of 
construction, but it is also the post-there CONTAINED ENTITY/EVENT that influences the type of container-space that is built.

(37) When two children from the remote village of Mayibout, in Gabon, discovered a dead chimpanzee lying in the undergrowth near their home a few weeks ago, they were delighted. Bush meat is a delicacy throughout the rain forests of central Africa, and chimps are particularly prized for their size and scarcity. Villagers helped carry the primate back to Mayibout, where it was skinned, cooked and eaten. There, nearly all those who had prepared the animal for the pot fell ill with a high fever. Some began bleeding from the eyes and mouth. By last week thirteen were dead.

With this modification locative there gives an ambiguous reading. Locative there could be interpreted either as a 'pure' locative space or as a temporal space. If the reader associates the locative there with the village of Mayibout then the interpretation is 'pure' locative space. However, if locative there associates with the sequencing of temporal events, the interpretation of locative there will be temporal. The contained item that follows is compatible with both types of readings which, therefore, makes locative there ambiguous in this modified passage.

If one thinks in terms of the necessary condition that the CONTAINER-SPACE must correspond to the CONTAINED ELEMENT for a felicitous reading, this more clearly explains the factors that have overridden a purely locative reconstruction in (36). In the original passage, locative there has associated with the temporal sequencing of events to construct a TEMPORAL CONTAINER-SPACE which felicitously corresponds to the CONTAINED TEMPORAL EVENT, the festivities ended. The temporal reading is further confirmed by another indicator of temporal sequencing, within a week.

Thus, we can see that an abstract temporal space is configured by association with temporal expressions, and that the absence of a potential spatial referent is not a necessary condition for a temporal reading. It is rather that the configured container-space must correspond to the events that will be situated within it. In other words, the CONTAINER must fit the CONTAINED entity or events. These observations are reflected in and validate the associative model. The model has also proven its validity by uncovering a basic referring condition according to which container-space and contents must be compatible with each other. 


\subsubsection{Temporal-narrative associations: Temporal-narrative space}

At first glance, the following token also expresses a temporal reading which is confirmed by the absence of any spatial referents in the co-text:

(38) [...] for years. Says Nihn: 'My war experience always haunted me and asked me to write it down. I can't remember the day I started, sometime in 1985.

Kien takes over from there. The fictional author forces the reader and himself through a 'parade of memories' that 'push upstream like a sampan toward the past.'

[Colmey, J., "The other side of hell," Time, 27/06/94, p. 57]

The associative potential of there allows it to match up with the temporal constituents, started, sometime in 1985 and construct a temporal space which can be paraphrased 'at that time.' Once again the TEMPORAL CONTAINER corresponds to the constituent(s) being CONTAINED within that space; Kien takes over is the event that is situated into 'at that time,' and it implies a sequencing of events. This is corroborated by the expression that follows, a parade of memories, which also implies a sequencing of events.

Interestingly, further analysis of this token shows that the temporal space being configured has the added twist of being at the juncture between the "event time" of Nihn's real war experience and the "discourse time" (Dorgeloh 1997: 190) of the fictional Kien's parade of memories. These expressions indicate that there is a sequencing of a story, and they too contribute to reconfiguring space into what can be considered, in final analysis, a temporal-narrative space which can be paraphrased as 'at that point in the narrative.' The indicators of narrative sequencing occur both before and after the use of there, and condition and correlate with the container-space.

This token shows the potential of locative there to form temporal and pragmatic associations that allow for the reconfiguration of more abstract kinds of space, i.e. temporal-narrative space. Furthermore, this example confirms the model proposed for locative there in that there serves as a situator via constructive associations. 


\title{
4.1.2.4 Pragmatic associations
}

It is a recognized fact that language interweaves general world knowledge into spoken and written discourse. These 'understood' relations are what allow people to make pragmatic associations that link world knowledge into the discourse realm. This is evidenced in the following case of locative there where there are no endophoric referents and yet pragmatic associations are made:

\begin{abstract}
ADVERTISEMENT FOR THE CHEVY ASTRO
The Chevy Astro LT understands what it's like to be a kid. Kids have stuff. We have over 170 cubic feet of cargo space. They have friends. We can sit up to eight. They get bored. We have reading lamps and a place to play board games. And because Astro has a powerful Vortec V6, you'll already be there before they whine, 'Are we there yet?' Astro, from Chevy Trucks. [...]
\end{abstract}

[Chevrolet advertisement, Time, 11/03/96]

Here, it can be inferred that the second occurrence of locative there means 'a destination' or 'having arrived at a particular place.' The reader reaches into the realm of world knowledge where it is known that trucks go to and arrive at 'places.' The words such as truck and Chevy, and the italicized text that implies 'keeping kids occupied during a trip,' as well as the accompanying picture of a car, provide the input for the pragmatic associations which allow there-space to be configured into a 'destination.' Moreover, the child's question can only be interpreted as locational.

This example validates the model in that there forms associations that allow for pragmatic inferences to configure its space. It also provides further evidence that locative there functions not by substitution but by association, be it textual, situational or pragmatic.

\subsubsection{There + PP - cataphoric associations?}

Cataphoric referencing implies that the referring expression is forward-looking, and associates with a referent expression that follows. The corpus analysis of locative there has revealed three things about cataphoric referencing. First, the referent PP comes immediately after locative there: 
(40) I lay there on that slimy table while Mr. Tanaka examined my lip,[...] We stared at each other for a long moment--so long it gave me a chill even there $\rightarrow$ in the muggy air of the seafood company.

[Golden 1997: 14-15]

Second, when locative there $+\mathrm{PP}$ is positioned pre-verbally, it actually associates both anaphorically and cataphorically with given and new locative information. Unfortunately, this is not recognized in the literature, where it is assumed that locative there in such cases refers either anaphorically or cataphorically. For example, Birner (1996:25) describes locative there in example (41) as anaphoric, whereas Dorgeloh describes a similar instance in (42) as "cataphoric to the following locative constituent" (1997: 52):

(41) We drove down a lane of poplars, past a wide lawn on which sheep grazed, and $\leftarrow$ there, around the curve, lay the monastery-a large farmhouse with wings added on, enclosed by a high wooden wall.

[Colwin 1990: 218 - token provided by Beth Levin]

(42) There, $\rightarrow$ outside the villages, were fields with vines.

Analysis of example (41) shows that the post-there PP, around the curve, is actually a further specification of a previous given setting the lane and the preposition past; that is that the monastery is situated not only past the wide lawn but also after the curve in the lane. Hence, locative there serves as a link between given and new locative information in the post-there PP to re-specify a space.

In the case of example (42) above, although Dorgeloh claims the token is cataphoric, insufficient context is available for analysis. My corpus showed that all such cases of clause-initial locative there, the PP that followed was a re-specification of some previous spatial constituents. Indeed, two corpus examples of clause-initial locative there $+\mathrm{PP}$ are provided below which show the relationship of a given location and the new specification of the post-there PP: 
(43) Though he knew better, Father saw each of his sons as Confucian scholars, as if his B.C. Chinatown boys could reflect the Old China he himself remembered as a child. $\leftarrow$ There, $\rightarrow$ in Sun Wu village in the county of the Four Districts, if a boy was not too poor, [...] he looked forward to an encounter with reading and writing.

[Choy 1995: 186]

(44) When I went out, Auntie was waiting in the upstairs hall with a chore for me. She gave me a bucket and sent me up the ladder through a trapdoor onto the roof. $\leftarrow<$ There $\rightarrow$ on wooden struts $>$ stood $<\mathbf{a}$ tank for collecting rainwater. $>$

[Golden 1997: 51]

In (43), locative there associates both anaphorically with the previous locative constituent, Old China, and cataphorically with the post-there PP, in Sun Wu Village, in the county [...], which gives further specification of the Old China. In (44), which is a locative inversion, the same thing occurs. Locative there associates anaphorically with onto the roof which is further specified by the postthere PP, on wooden struts.

Thus, when clause-initial locative there is followed by a PP, it associates with both preceding given constituents and new locative information in the PP to construct a re-specified containerspace. A simple modification of the above passages confirms this double association. The modification also demonstrates that the use of locative there is sometimes obligatory as in (44). Examples (43) and (44) are repeated below without there as (45) \& (46):

(45) Though he knew better, Father saw each of his sons as Confucian scholars, as if his B.C. Chinatown boys could reflect the Old China he himself remembered as a child. In Sun Wu village in the county of the Four Districts, if a boy was not too poor, [...] he looked forward to an encounter with reading and writing.

(46) When I went out, Auntie was waiting in the upstairs hall with a chore for me. She gave me a bucket and sent me up the ladder through a trapdoor onto the roof. $<$ On wooden struts $>$ stood $<a$ tank for collecting rainwater.>

In (45), which is a case of adverbial fronting, the relationship of the given and new locative information can be inferred because countries are assumed to contain villages. However, in the case 
of example (46), the locative inversion is infelicitous without locative there. The reason for this is that the pre-verbal PP, on wooden struts, represents information equally as new as that in the postverbal NP, a tank for collecting rainwater. Birner's study of inversion (1996: 83-103) demonstrates that the pre-verbal PP of a felicitous inversion must in some way be "discourse-old information." That is, it should be inferable or evoked information, and thus connect with previously given information. In example (46), the pre-verbal PP, on wooden struts, has not been previously evoked, nor can it be inferred from roof because roofs do not usually have struts. Consequently, the newinformation status of the pre-verbal PP renders the inversion infelicitous. However, when locative there is used, it makes the inversion felicitous by connecting both given and new locative information. As such, locative there allows a reader to mentally connect the wooden struts to the roof. The result is that the new information in the pre-verbal PP, wooden struts, is given access to the 'discourse-old' information, roof, an information status it requires for felicitous inversion.

In brief, clause-initial locative there when followed by a PP associates both with previous given locative information and with the new locative information in the PP. In addition, it is the new locative information of the PP that re-specifies the container-space.

A third observation that applies to certain cataphoric cases of locative there is that they could be considered 'redundant' or 'optional' uses, a characteristic reminiscent of existential there. ${ }^{20}$ More precisely, locative there can be used in contexts that do not require its use for situating entities. In these cases, an emphatic effect is produced by creating a contrast wherein the configured container-space does not correspond to the contents.

The following example provides an original passage with such a 'redundant' use of there in (47a), a passage that has been modified by removing there in (47b). Both readings are equally felicitous, demonstrating that there is not necessary to situate the face above the collar of the elegant kimono.

20 The notion of an 'optional' existential there was common among early transformationalists (i.e. Kuno 1971; Lyons 1967), accepted by Breivik (1981) and was closely related to the notion of a meaningless there. 
(47) a. Now she took a closer look at me for the first time, $[\ldots]$ I was so curious about her that my eyes took on a life of their own. The more I saw of her, the more fascinated I became. Her kimono was [...] Her obi was [...] Every detail of this woman's kimono was enough to make me forget myself. And then I came upon a rude shock: < for there above the collar of her elegant kimono $>$ was $<a$ face so mismatched to the clothing $>$ that it was as though I' $\mathrm{d}$ been patting a cat's body only to discover that it had a bulldog's head.

[Golden 1997: 41]

b. Every detail of this woman's kimono was enough to make me forget myself. And then I came upon a rude shock: <for above the collar of her elegant kimono $>$ was $<$ a face so mismatched to the clothing $>$...

However, there is a clear difference in the two readings in that each produces a different emotive effect. In (47a), the 'redundant/optional' use of locative there + PP produces an emphatic effect, whereas a more neutral reading is observed without there in (47b). This seems to be a case when there is used for both semantic and phonetic reasons. Semantically, the opposition 'there vs. some other possible place' is exploited to convey the idea of this being where one would least have expected to find such an ugly face (namely, above such an elegant well-proportioned body). Phonetically, it allows contrastive stress to be focused on a one-syllable word.

In sum, the above analysis of the cataphoric associations of locative there has revealed three features. First, when there are cataphoric associations with a referent PP, the PP immediately follows locative there. Second, when this syntactic ordering occurs clause-initially, locative there associates both anaphorically and cataphorically, connecting previously given locative information and new information to re-specify a container-space wherein an entity or event can be situated. Moreover, when this pattern is used in a redundant way, locative there produces an emphatic effect because it evokes a container-space that contrasts with the type of location where one would have expected to find the event or entity situated within it; it thus produces a feeling of surprise, of the unexpected. This latter use fully exploits the function of there because by not meeting the condition that a container-space correspond to the contained entity/event, it reaches into the realm of emotivity where expectations are not realized and disappointment is produced. 


\subsubsection{The associative function of locative there summarized}

In summary, all the cases of locative there examined so far validate the proposed model according to which there functions by forming associations. These associations configure the previously undefined space of there into a CONTAINER-SPACE wherein entities or events are situated. Analysis has also revealed a normal condition of the associative process, which is that the CONTAINER-SPACE must correspond to the CONTENTS contained within its space (see section 3.3.1). This condition is sometimes countered by using a containee which does not fit the container, inevitably producing an effect of surprise (see section 4.1.2.4). However, the effect of surprise produced by such cases is a further demonstration of the validity of the proposed model.

Finally, the use of locative there provides the universe of discourse with a 'package-deal': the open there-space both serves as a foundation for spatial constructions and via its associative potential provides the inherent connective capacity used to configure space to fit the needs of context.

\subsubsection{The functional correlation between locative and existential uses of there}

At this point, it is pertinent to highlight how certain functional characteristics of the locative use of there are similar to those that are found with existential there.

First, locative there can function to RE-SPECIFY a broader location into a more specific location (cf. section 4.1.2.5 on cataphoric associations), an observation which also applies to the existential use of there, which tends to RE-SPECIFY a broader discourse topic into a sub-topic that is introduced into discourse in the post-verbal NP (Dorgeloh 1997: 109; Erdmann 1976; Sasaki 1991: 157). This is illustrated in the following example:

(48) EXISTENTIAL THERE: It's the line of choice we each have that separates smart risk from stupid risk. Maybe you love to windsurf or roller blade or just cruise around. $\leftarrow$ There are $\rightarrow$ five things you can do to take smart risk: look first. Wear the gear. Get trained. Drive sober. Buckle up. [...]

[Advertisement: The stupid line, Injury Prevention Foundation] 
Here, existential there introduces a subtopic, five things [that young people] can do, which is actually a specification of the broader topic, smart risk.

Second, analysis of the locative use of there has demonstrated that it has an inherent CONNECTIVE CAPACITY. It links entities or events into its linguistically configured space; moreover, it connects new locative constituents to given locative constituents (example 44). Similarly, existential there CONNECTS given information with new information (Dorgeloh 1997: 66; Huckin \& Hutz-Pesante 1988: 380$){ }^{21}$ it provides what can be called a LOCUS OF EXISTENCE wherein discourse-new entities or events can be situated, as is illustrated in example (49a) which is paraphrased in (49b):

(49) a. Jonas grows up in a perfect world. $\leftarrow$ There's $\rightarrow$ no crime, no fear, no pain.

[Children's Book of the Month Club Review, August 1999, p. 27]

b. Jonas grows up in a perfect world where no crime, no fear, no pain exists.

Both of the similarities pointed out above suggest that the associative model proposed for the locative use of there (page 32) can also be applied to the existential use of there. Indeed, the model can be reformulated to express the associative capacity of existential there (see model on following page), thereby showing more clearly the correlation between the two uses. In essence, both the locative and existential uses of there can be considered situators with an inherent connective capacity that is based on there's associative potential.

${ }^{21}$ See also Allan 1971:16; Aniya 1992:161; Bolinger 1977:93; Breivik 1977:337; Chafe 1976:32; Sasaki 1991:161. 


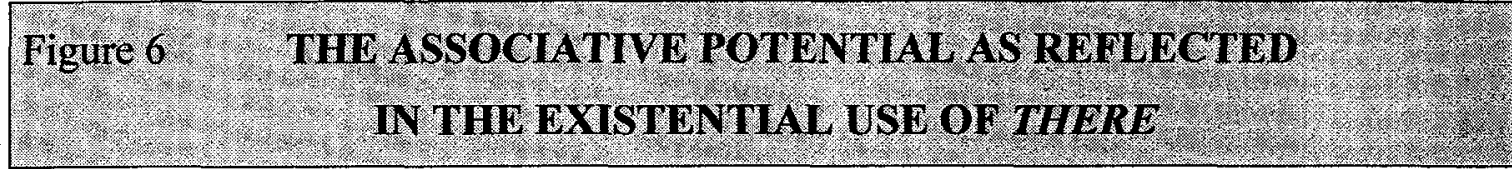

\section{\#1 Non-constructed Open Space}

There

\#2 Association at Discourse Level

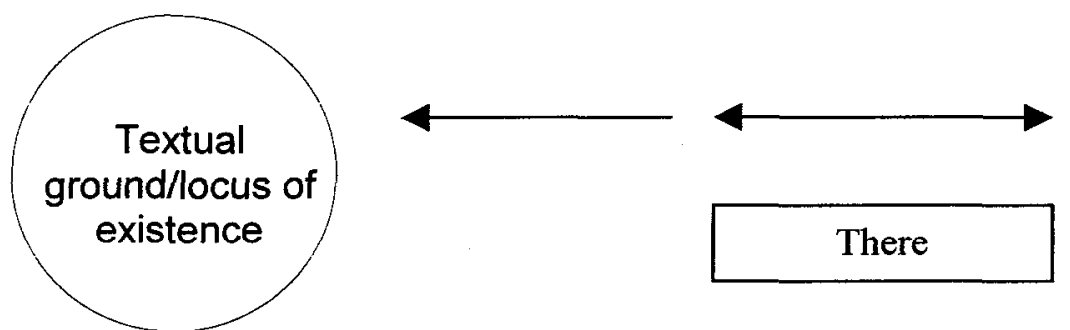

\section{\#3 Reconfiguration of Container Space}
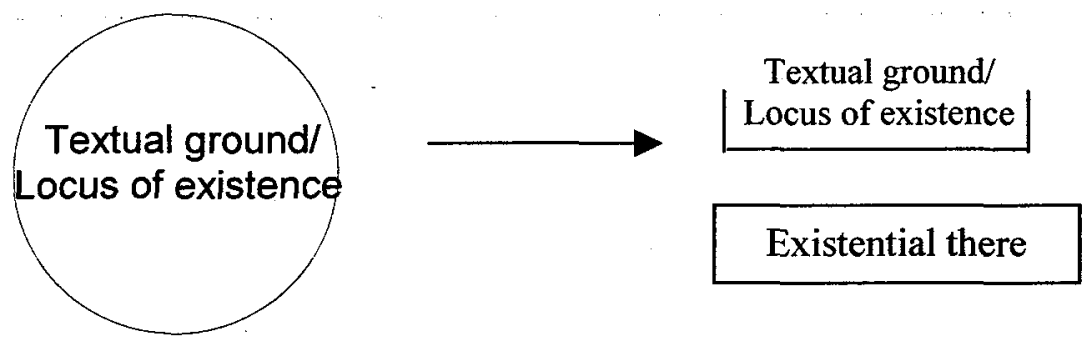

\#4 Connection of topic/subtopic or given/new
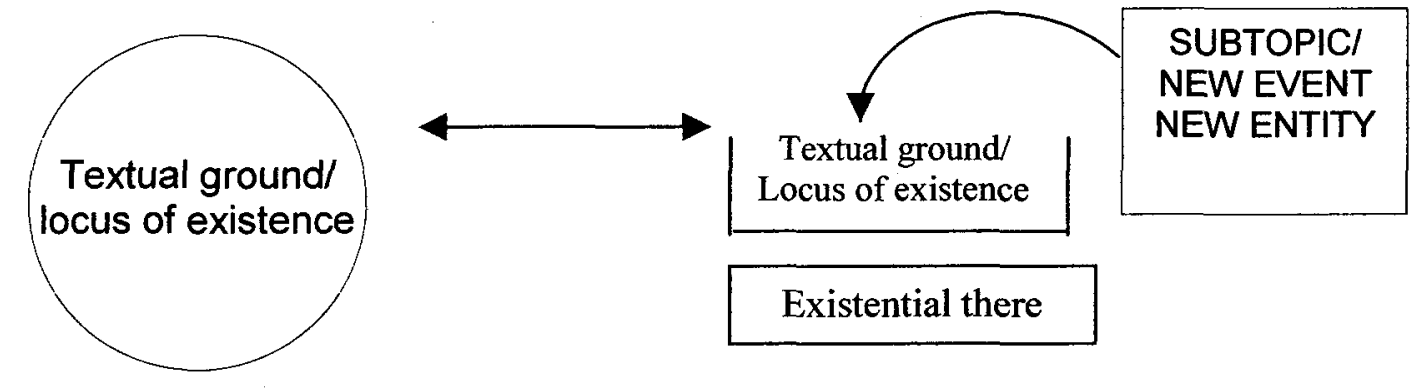

Existential there 
The model can be depicted more simply in the following diagram that shows the parallels in the connective capacity of both uses:

\section{Figure 7 The Connective Capacity of Locative and Existential There}

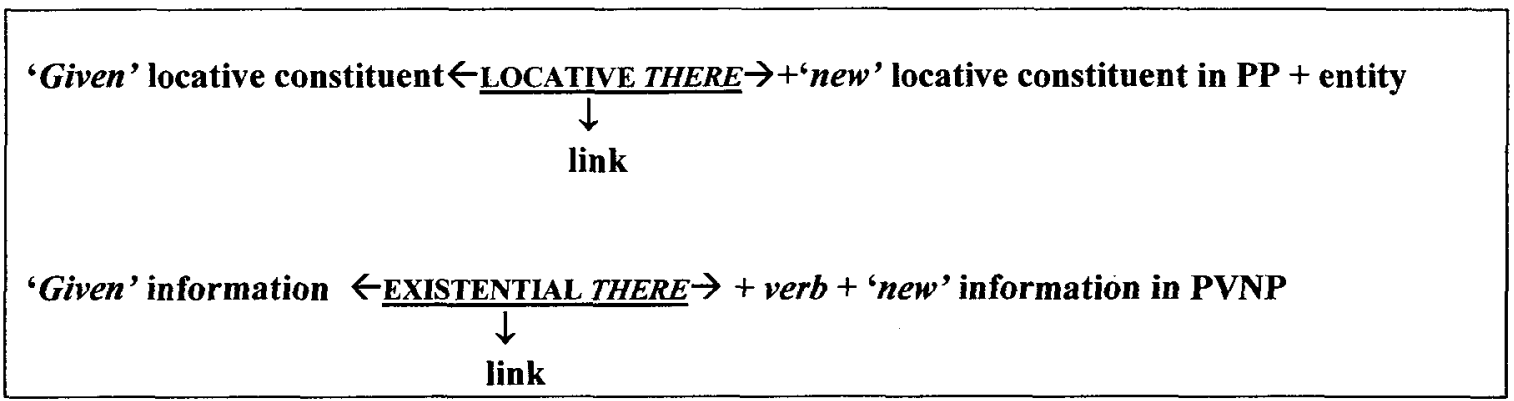

In sum, there can serve as a link between prior 'given' constituents and the post-there 'new' elements. The fact that this model applies equally well irrespectively of the locative/existential dichotomy is evidence of the unitary nature of there.

A third similarity in the two uses of there corresponds to one of the features of the 'real-life' use of space. In sections 3.4.1 and 3.4.2, it was noted that space tends to be defined by the contents that are to be situated within it. As such, if the two uses of there are derived from the same potential meaning, one should expect that if one of the uses reflects this condition, the other would too. In effect, it was noted that locative there does make use of this condition to felicitously configure space and to produce expressive effects. Similarly, the existential use of there also respects this condition.

This correlation can be observed in the differing contents that their linguistically configured container-spaces can contain. Since the space configured by the locative use of there is semantically different from the existential use, its container-space should exhibit differing contents. Indeed, research has observed that the verb and the post-verbal constituent of inversion (of which locative there is a subset) is subject to a constraint that does not apply in the case of existential there constructions. More precisely, locative inversion generally does not allow negation, whereas this notion is perfectly compatible with the existential use of there. 
Birner notes that out of 1778 inversions there is not a single token with a negated verb which suggests the "negation of the verb in inversion seems impossible" (1996:151):

(50) *Into the room didn't walk John.

[=Birner 1996: 151, ex. 7]

(51) * She gave me a bucket and sent me up the ladder through a trapdoor onto the roof. $<$ There on wooden struts $>$ didn't stand $<$ a tank for collecting rainwater. $>$

[Golden 1997: 51]

Similarly, there appears to be a restriction on the post-verbal constituent. Out of the 1778 tokens of Birner's corpus, she states that there are three with negated post-verbal constituents. However, the only example she provides, (52) below, is categorically an affirmation even though syntactically it is a negation.

(52) Now, the warm silence pressed in, thick as a fog. $<$ From below, from Mrs. Abney's domain, > came < no sound >. Perhaps she had taken herself out or was still asleep. (...came silence)

[=Birner 1996: 153, ex. 10d]

This "incapacity to be negated" (Dorgeloh 1997: 118) makes semantic sense in that the presentational function of inversion is to set up a stage on which items that are assumed to exist are to be situated. Pragmatically, it would be counter-productive to set up a stage and not situate something on that stage.

By contrast, the existential there construction functions at the very level of existence. Consequently, its presentational function sets up a locus of existence wherein items and events can be asserted or denied. This existential 'stage' is obviously compatible with negation whereby 'items' are denied existence. In effect, this construction allows for both negated verbs, as in examples (53) and (54) below, as well as negated post-verbal constituents as in (55): 
(53) $[\ldots]$ meticulously stitched so there's not a smidge of irritation.

[Lands' End Kids' Catalogue, Spring 1999, p.16]

(54) There did not appear the very one we needed most.

[=Bolinger 1977: 122, ff. 19]

(55) When they reached Meiying's room, there was no movement [...]

[Choy 1995: 237]

Of the 324 existential constructions in my corpus, there were a total of 76 negations, 14 of which were negated verbs and 62 of which had negated post-verbal constituents. This data shows a marked contrast with Birner's data for inversion which applies to locative there in locative inversion. It shows that the differing container-spaces of the 'two' theres are subject to different constraints. Existential space allows for negation, whereas 'referential' space does not. In turn, this difference reveals a correlation in the two uses of there: both uses respect the condition that container-spaces must correspond to the thing contained.

In sum, it has been shown here that features of a so-called 'locative' use of there correlate with the existential use. More specifically, both uses of there can serve to re-specify previously given information, both have an inherent connective capacity, and both respect the 'natural' condition that container-spaces correspond to the entities and events contained within them.

\subsection{The role of stress in the realizations of there}

Stress is commonly used as a formal argument to distinguish locative there and existential there in the literature. However, if both uses are inherently a single word with the same potential meaning, there are undoubtedly underlying principles that govern the actualizations of a stressed or unstressed there, principles that need to be discovered. A return to pronominal studies proves helpful since locative there is considered a pronoun and it is generally assumed that conclusions regarding pronoun stress apply to locative there. In section 4.2.1 below, factors which do not 
influence the phonological realization of there are discussed, which allows for a more focused starting point in the analysis of the data in section 4.2.2.

\subsubsection{What pronoun stress reveals about the phonological realization of locative there}

This section shows that the notions of anaphor/cataphor and given/new information have no incidence on the phonological realizations of there. In the end, this leaves contrastive stress as the one factor that may be of influence. This is highly plausible considering the fact that both uses of there may occur in the same syntactic space and some means of distinguishing them is necessary.

It has been observed that anaphoric pronouns, which refer to antecedents in the preceding text, are generally unstressed, an observation which has been assumed to apply to locative there (Bardovi-Harlig 1983: 15; see also Horn 1978; McCawley 1971, Green 1969). Analysis of the corpus, however, has revealed that this is not the case; locative there is usually stressed (indicated by bold type below) even though it refers to a linguistic antecedent:

(56) "On sunny days, we ran anxiously to Powell Ground to see if Kazuo would be able to meet Meiying by the bench under the tree. $\leftarrow$ There, Meiying would tell me what Kazuo had said to her at school that day,"

[Choy 1995: 226]

It can be concluded then that anaphoricity is not a condition for locative there to be de-accented, as is the case for pronouns. In a similar vein, corpus analysis has shown that cataphoric referencing makes no difference in the phonological realization of there; it is stressed in such cases:

(57) Bruno was not unhappy there $\rightarrow$ at Wain College $[\ldots]$

[Golding 1939: 47]

Unstressed pronouns have also been linked to the notion of given information, following the general tendency in English to convey given elements in "a weaker more attenuated manner than 
new information" (Chafe 1976: 31). ${ }^{22}$ Indeed, anaphoric pronouns do refer to given information and are unstressed (unless they are contrastive). Once again, this is not the case for locative there; despite representing given information, anaphoric there is stressed:

(58) I almost felt sick the first time she unfastened her robe and pulled it down from her shoulders, because the skin $\leftarrow$ there and on her neck was bumpy and yellow like an uncooked chicken's.

[Golden 1997: 47]

In her study of inversion, Birner makes note of a similar discrepancy. A sampling of 80 tokens judged for intonation patterns and their relationship with given information reveals that the anaphoric/deictic elements 'thus,' 'here,' 'this,' and 'then' were judged non-deaccentable “despite representing textually or situationally evoked information" (1996: 129-130). Locative there falls into this category of anaphoric elements which are stressed despite evoking given information.

It can, therefore, be concluded that the phonological realization of a stressed locative there does not conform to the principle that given information be "pronounced with a lower pitch and weaker stress" (Chafe 1976:31). This suggests that if there are any principles governing the actualization of a stressed and unstressed there, they are not related to anaphoric/cataphoric relations nor to given and new information status.

Another observation concerning pronoun intonation patterns hints at what the role of stress could be in a single there model: anaphoric pronouns can be stressed to establish a contrast of some sort. $^{23}$ This feature conforms to the more general principle noted by Chafe in which given information can be stressed when it is contrastive (1976: 31). In the following example, the pronoun 'she' is unstressed in (59a) because the normal condition of subject continuity is satisfied. That is,

${ }^{22}$ Comments on the correlation of information status and stress can be found in a variety of other sources, see BardoviHarlig 1983: 21; Bolinger 1961, 1972: 633; Givón 1993: Vol. I, 236; Halliday 1970: 163; Penhallurick 1984: 41; Tasmowski \& Verluyten 1982.

${ }^{23}$ Pronouns can signal various kinds of contrasts through stress. Besides the switch-of-subject contrast, Givón also suggests that stressed pronouns can signal thematic contrast (1993: Vol. I, 238). 
'she' can 'only be interpreted as co-referent with 'Mary,' which is the subject of the preceding clause." In (59b) the interpretation changes when 'SHE' is stressed; in this case, 'SHE' can only be "co-referent with 'Suzy,' which is the object of the preceding clause. The stressed pronoun in (59b) thus affects a switch-of-subject” (Givón 1993: Vol. I, 236):

\footnotetext{
(59) a. UNSTRESSED: Mary told Suzy, then she told Sally.

b. STRESSED: Mary told Suzy, then SHE told Sally. [=Givón 1993: Vol. I, 236, ex. 63]
}

Thus, stress is used to signal contrast; here the contrast is a pronoun interpretation that is "counternorm, whereby referential identification is more problematic" (Givón 1993: Vol. I, 237). Under normal conditions, anaphoric pronouns are unstressed because they encode given information; stress is then a signal that there is to be a 'change in interpretation,' or in other words, a change in sense.

Stress is also used elsewhere in English to denote contrast. For instance in example (60a), stress is used to set off the speaker as the person who was told, as opposed to those who were not told. The contrast can also be left implicit as in (60b):

(60) a. She told ME, not Bob.
b. She told ME.

(61) Put that book THERE.

This seems to resemble the role of stress with the locative use of there where there is an implicit contrast between the place designated by there and any other place, as is illustrated above in (61).

In sum, it can be concluded that the intonational realization of locative there is not related to anaphoric and cataphoric associations or to given and new information as for pronouns. Rather, stress may be playing a contrastive role where it signals a distinct meaning. An attempt will be 
made here to contribute to a better understanding of how it operates with there, although this is an area in which many aspects of the complex phenomenon of intonation remain to be explored.

\subsubsection{Stress phenomena as it relates to a new discourse structure, 'verb + there,' a link to existential there}

In the literature, the difference in the phonological realizations of existential and locative there is considered as evidence that the two theres are distinct words. For instance, Dorgeloh states that stress is the "most substantial criterion [...] to distinguish" locative there from the existential (1997: 52; see also Birner 1996: 25). However, analysis of the corpus has revealed that statements such as this need to be reconsidered because there are attested cases of unstressed 'locative' there. These cases challenge the assumption of a distinction between two theres.

Discovered in the corpus was a discourse segment in which two actualizations of 'locative' there could occur, one stressed and the other unstressed. These two actualizations form a minimal pair in the discourse construction 'VERB + THERE':

$$
\begin{aligned}
& \text { a. You sit THERE. (unstressed verb and stressed there) } \\
& \text { b. You SIT there. (stressed verb and unstressed there) }
\end{aligned}
$$

An informant reaction test unanimously concluded that the two phonological realizations in (62) correlated to meaning variations. In (62a) when there is stressed relative to the accompanying verb, locative there refers to a particular location and can be paraphrased as, 'I want you to sit in that particular spot instead of any other,' producing a contrastive effect. On the other hand, when there is unstressed (62b) and the preceding verb stressed, there evokes a 'motionless' effect. Indeed, it was qualified as a command, 'sit and don't you move!,' something a mother might say to her hyperactive child. Here, the specific place of sitting is of no importance, it is the 'you be sitting and nothing more' that is being emphasized. In sum, stress in this minimal pair is contrastive and signals an interpretation opposing one place to any other. 
The pattern described in (62) is not an isolated occurrence. The corpus provided many such tokens in which a stressed verb was followed by an unstressed there with an accompanying nuance in meaning. Neglected and unnoticed at first, an in-depth analysis of this discourse segment showed that there are other features which distinguish this 'new' use of there from a stressed locative use.

The first feature is the 'optional' nature of the unstressed there. The term 'optional' is borrowed from early discussions of existential there where the following locative inversion (63a) was considered equivalent to the existential there construction (63b), so that there was considered an 'optional' element which added nothing to the truth-value of the sentence:

(63) a. In the garden was a unicorn.

b. In the garden, there was a unicorn.

Similarly, the 'optional' use of there in (64a) below does not change the truth-conditions of the proposition. In both the original and the modified passage, the girl standing is situated within the space of the PP, on the dirt corridor, regardless of whether there is present or not. Hence, there is not being used to make a locative connection:

(64) a. The more I saw of her, the more fascinated I became. Her kimono was [...] Her obi was [...] The more I looked at her clothing, the less I was aware of standing there on that dirt corridor, or of wondering what had become of my sister [...]

[Golden 1997: 41]

b. The more I saw of her, the more fascinated I became. Her kimono was [...] Her obi was [...] The more I looked at her clothing, the less I was aware of standing on that dirt corridor, or of wondering what had become of me [...]

This so-to-say 'optional' use of there can be compared to the 'obligatory' use illustrated below in example (65a), in which the post verbal locative there is needed to situate an item in a particular space: 
(65) a. He put his hand into his coat-pocket to take out a handkerchief and found it cluttered with the tricks and gadgets he had stuffed there the last moment before coming downstairs.

[Golding 1939: 44]

b. ?He put his hand into his coat-pocket to take out a handkerchief and found it cluttered with the tricks and gadgets he had stuffed the last moment before coming downstairs

The passage modified without there in $(65 \mathrm{~b})$ is infelicitous in terms of the intended locative association. In addition, the propositional meaning differs. In (65a), it is the coat pocket which is stuffed with tricks and gadgets, whereas in (65b), it is the tricks and gadgets that are stuffed. In sum, unstressed there is not being used as a locational situator, but for some other purpose.

A second feature of this unstressed use of there is that it can be qualified in traditional terms as 'non-referring' because it does not 'refer' to a 'particular' place as does a 'referring' there. Examples (66) and (67) below illustrate that this 'new' use can occur in propositions that have no locative constituents:

(66) $[\ldots]$ We just stand there and shoot.

[phone conversation with Leif French describing goose hunting, September, 1999]

(67) Rodney Brooks gushes like a first time parent about the things his baby can do. 'It sits there waving its arm, reaching for things,' he says. These are pretty standard tricks for newborn humans, [...]

[Dibbell, J., "The race to build intelligent machines," Time, 01/04/96]

These examples show that there cannot be 'referring' since there is nothing to which it can refer: it does not denote a particular place. This brings to mind existential there, which does not evoke a specific place and is qualified as 'non-referring' because it can be in a proposition which "may contain no locative information at all" (Dorgeloh 1997: 52).

It is at this point that the traditional notion of 'referring' becomes inadequate and the notion of 'association' appears more appropriate to describe the various kinds of relations that locative 
there entertains. There still functions in relation to other items in the context to configure meaning; as such, these relations are better termed 'associations.' For instance, in the following example, even though there does not denote a particular place, the sense of 'inactivity' or 'immobility' which it evokes is produced by the association of the verb and there: unstressed there ASSOCIATES with the stressed verb to form a container-space that is defined by the very space required for the state or action denoted by the verb. The entity involved in the event is thus situated within the confines of this restricted container-space, which evokes the sense of 'motionlessness':

(68) I was so dazed as I stood there, with so many thoughts running through my mind $[\ldots]$ shocking to me in their ugliness that I could do nothing but stand there staring at them.

[Golden 1997: 41]

When followed by there, the verb merely evokes a 'manner of occupying space' or the mere occupation of space' which suggests that the de-emphasized meaning is configured by the interactions of there and the verbs stood and stand. These verbs then can be qualified as informationally light since they do not evoke a sense of activity but rather merely a manner of occupying space.

This change in verb meaning in the context of an unstressed there parallels similar observations made for the existential there construction. There, the verbs have been qualified as 'de-emphasized' or 'informationally light' because they, too, do not express an active sense of the verb (see section 2.2.2.2).

A third feature of this new 'optional' there is at the semantic level. Unstressed there contributes meaning that is distinct from the meaning of stressed there, which denotes a 'particular place,' and which differs from its non-use. Its distinct meaning was confirmed in an informantreaction test given to check suspicions that 'optional' there was behaving distinctly from locative there. Ten native English speakers were asked to evaluate the following minimal pair and determine if the removal of there in sentence $(69 \mathrm{~b})$ would affect the overall meaning of the original passage in (69a). If so, they were asked to qualify the effects of both. 
(69) a. The cease-fire has been agreed upon.

The doorway immediately fills with soldiers and officials. Everyone is very upset. We want to leave the room but cannot get out. Finally the entrance clears and we push our way through. The Polish woman quietly brings me my coat and quickly excuses herself: at the moment she can do nothing for me. But she calls to someone on the floor who can help us. So we stand there in the corridor in the general excitement and confusion.

[Döblin 1992: 159]

b. [...] So we stand in the corridor in the general excitement and confusion.

The results were unanimous. Not only did everyone agree that both sentences produced very different effects, but they used similar qualifications to describe these effects. Sentence (69b) without there produces a neutral tone, an effect which is reflected in the written comments made by the informants, for example, "lessens the intensity," "very relaxed," "more neutral vision." On the other hand, the original passage with there produces an emotive effect, also reflected in the comments, such as, "frozen, helpless, no movement," "lack of choice," "trapped." Hence, there in this discourse structure is being used to produce an effect of motionlessness with emotive connotations.

Analysis showed that a majority of the tokens with this use of there had atmospheres evoking a negative tone which justified the effect of motionlessness it produced. Besides example (69a) which has an atmosphere of general confusion and upset in a war setting, example (70) has a context in which a young boy is seriously ill and surrounded by concerned adults.

(70) And then, one day, the Boy was ill.

His face grew very flushed, [...] Strange people came and went in the nursery, $[\ldots]$ and through it all the little Velveteen Rabbit lay there, hidden from sight under the bedclothes, and he never stirred, for he was afraid that if [...]

[Bianco, M., The Velveteen Rabbit, 1994, p. 25]

These examples can be contrasted to the non-use of there which is also warranted by context. For example, (71) below has a neutral tone which fits the context of a scene after the Boy's illness: 
(71) The boy got better. [...] It was a bright, sunny morning, [...] The Boy was going to the seaside tomorrow. Everything was arranged, [...] They talked about it all, while the little Rabbit lay under the bedclothes, with just his head peeping out, and listened.

[Bianco, M., The Velveteen Rabbit, 1994, p. 26]

Even though this use of there is compatible to negative impressions, it is not restricted to such contexts. In fact, it can be associated to emotions of surprise, of being deeply moved, or of fascination as in (72) below. It is also used where immobility is required of the situation, as in example (73) which describes goose hunting, or where movement is inherently impossible, as with the baby in (74):

(72) a. The more I saw of her, the more fascinated I became. [...] The more I looked at her clothing, the less I was aware of standing there on that dirt corridor, [...]

(73) [...] We just stand there and shoot. (a description of goose hunting)

(74) Rodney Brooks [...] gushes about the things his baby can do. 'It sits there waving its arm, reaching for things,'

In brief, since the meaning of this 'new' post-verb there evokes 'motionlessness,' it can be qualified as the 'frozen-state' use of there, which is opposed to the stressed locative use of there which configures a 'particular' space.

To conclude, the discourse segment VERB + THERE provides evidence for two things. First, it provides convincing evidence that stress is contrastive in the case of there. That is, stress operates on the same word, within the same syntactic structure to produce a message that differs in the absence of stress. Stressed there evokes a 'particular place,' whereas unstressed there evokes merely the space involved in the verb's event. Unstressed there can therefore occur in contexts that have no locative information.

Second, the discourse segment VERB + THERE exhibits striking similarities with both the existential there construction and locative there inversion. These two constructions will henceforth be combined and called the THERE-INVERSION construction. This simplifies an otherwise onerous task of labeling, and it more adequately represents inversion in terms of a unique there with a 
stressed and unstressed opposition that also occurs in the VERB + THERE construction. The two discourse structures are set side by side in Table 1, which highlights some of the parallels enumerated below:

1.) both syntactic segments can express two realizations of there;

2.) the two realizations correspond to phonological differences, one being stressed and the other unstressed;

3.) the phonological realizations correspond to meaning differences:

a. the unstressed use of there evokes meaning which is semantically light.

b. the stressed use of there evokes a 'particular place;' it expresses where an activity takes place.

4.) the unstressed theres can occur in contexts that contain no locative information at all, and therefore, could be qualified as 'non-referring';

5.) the verbs associated with the unstressed uses of there are de-emphasized. That is, they do not express a sense of activity; rather, they express a manner of existing or coming into existence (existential there), or a manner of occupying a limited space (verb + there).

To sum up, this new 'frozen-state' use of there offers convincing evidence that stress is playing a contrastive role with respect to a single there, and that the existential and locative uses of there are but two different realizations of the underlying meaning potential of the one word there. 


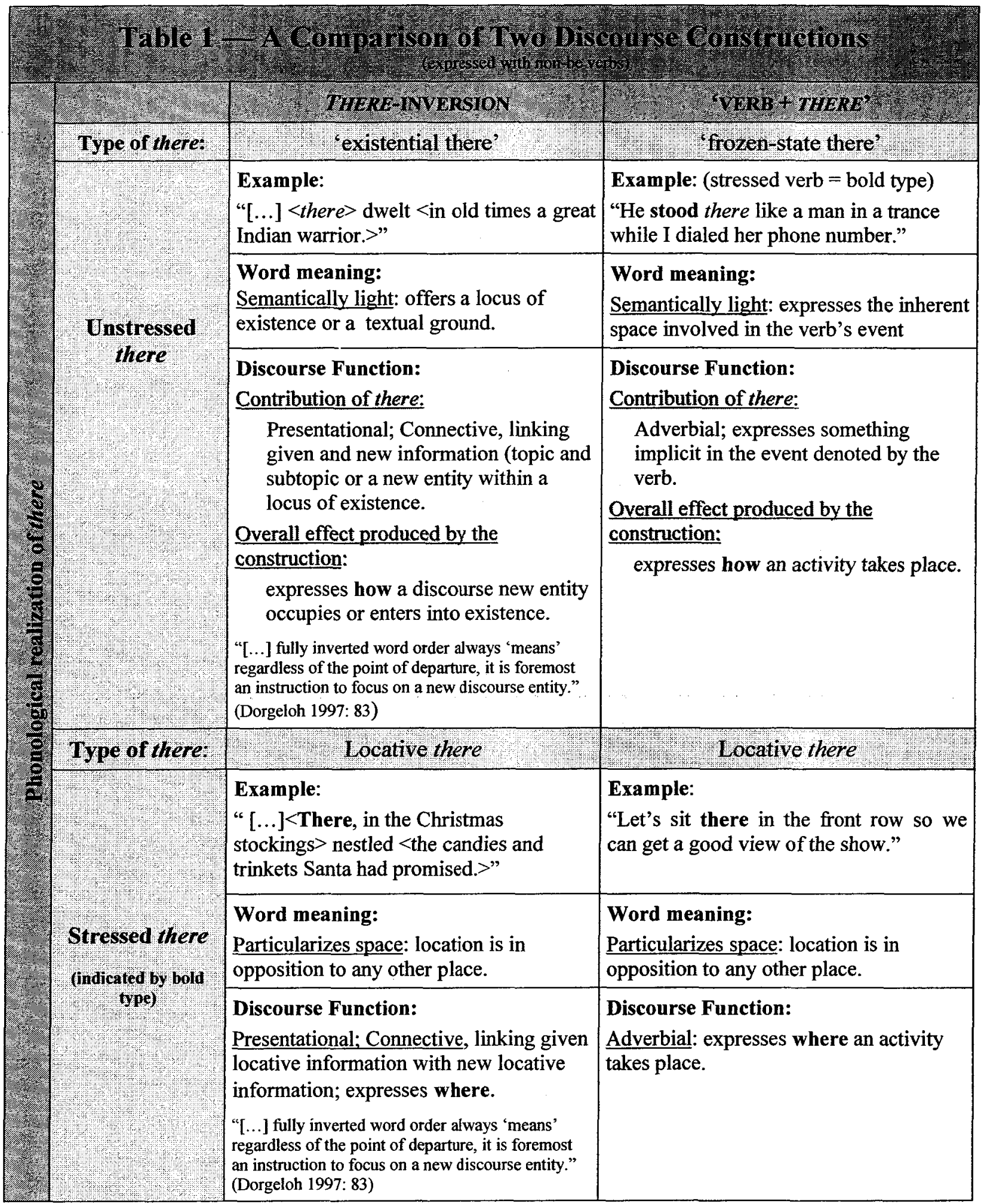




\subsection{Are there two uses of there in other syntactic constructions?}

Gordon and Scearce (1995: 321) state that "local discourse segments have a rich structure [which] may not be so intuitively salient as syntactic structures." Indeed, the syntactic segment VERB + THERE appears fairly unremarkable at first glance, and it is only upon analysis that it reveals that it functions as a local discourse construction paralleling the there-inversion construction: it allows two uses of there that are semantically and phonologically distinct. This discovery of a phonological and semantic opposition within a new discourse construction suggests that other less salient structures may also allow for such an opposition. Several tokens in the corpus do in fact provide evidence that this phenomenon occurs in other syntactic segments.

\subsubsection{Preposed-there}

PREPOSING is another discourse construction in which there can be realized in two distinct ways. This construction is characterized syntactically by a subject which is preceded by "some constituent that would canonically stand behind the verb" (Dorgeloh 1997: 54) and is illustrated in the following example with a preposed there:

(75) $[\ldots]$ by the bench under the trees. $\leftarrow$ There, // Meiying would tell me what Kazuo had said to her at school that day, [...]

[Choy, 1995: 218]

Examples (75) above and (76) below provide evidence of one of the ways in which there can be actualized within this construction. In both cases, there configures a particular location via spatial anaphoric associations:

(76) $[\ldots]$ Nato troops raided a ski chalet $\leftarrow$ about $40 \mathrm{~km}$ west of Sarajevo. $\leftarrow$ There, // they captured $11 \mathrm{men}$, including three Iranians [...]

[Nelan, B.W.., "With malice toward all," Time, 02/26/96] 
Phonologically, the above cases of locative there are stressed and are accompanied by an additional phonological marker; they are followed by a pause in oral communication, which is generally signaled by a comma in written texts.

In contrast, the cases of there in (77) to (80) below have a different prosody and express a different semantic content:

(77) There we go! (comment by $\mathrm{CBC}$ television sports commentator at the Montréal Tennis Masters semi-final's match, 09/08/03)

(78) THE BOOK OF SUMMER (article title)

[...]

P2 For me, summer reading remains a sacred ritual. First, there's figuring out what to take $[\ldots]$

P3 To qualify as a good read, a book should have at least one of the following by the end of the season:

P7 [...] but Pain the book is buoyant, witty and wise.

P8 So, there you have it //: a singular woman with [...] These are a few of the friends [books] l'm spending my summer with. What about you?

[Timson, J., "The book of Summer," Chatelaine, July 2003, p. 42]

(79) A: [...] 'Well, you said you have an idea who got you out [of prison]?'

B: 'Yes Rose. You will think I am mad.'

A: 'Do you want to tell me?'

B: 'I will tell you. It was Elsie Silver.' The car gave a sudden lurch towards the ditch.

A: 'There you are!' he pointed out. 'What did I tell you?'

[Golding 1939: 30]

(80) 'A girl's blood, Mr. Tanaka?' [...] 'where we bring the fish?' $[\ldots]$ 'I'd say her blood will be the cleanest thing to hit this floor since you or I were born. Go ahead. Spit it out.' There I sat // on that slimy table, uncertain what to do.

[ Golden 1997: 15]

The phonological signal which distinguishes the above use of there from the particularizing locative use $(75 \& 76)$ is to be found in the overall intonational pattern of the utterance. In (77) to (80), there operates with other constituents as a phonological and informational unit, THERE + SUBJECT + VERB 
+ (OBJECT), which is signaled by a pause which comes after the verb or object. This pause allows the informational unit to form fixed expressions such as those in $(77-79)$.

As far as stress goes, it is not clear if all these cases of there are fully unstressed. In a test of example (78) where the article was read out loud, there was unstressed by the three informants on separate sittings. On the second reading by the same informants, two of them actualized there as unstressed whereas a third actualized it as stressed. This suggests that more testing is necessary before it can be determined whether stress plays a role in signaling a possible opposition between two uses of there in preposing. Nevertheless, a phonological opposition is signaled via the presence or absence of a post-there pause.

Semantically, this use of there can be better understood in relation to the discourse function of preposing which is to establish "a link to previously established discourse units" (Dorgeloh 1997: 55). Analysis of my corpus tokens has shown that this use occurs at some terminal point, such as the end of a task, a discussion or a search and it thereby evokes a sense of completion, accomplishment or even of discovery. Occuring at a situational end point, there can implicitly signal a turning point or the beginning of a new event, just as the end of a chapter can signal the beginning of a new one. As a result, there provides a link with the termination of one activity and situates an event and an entity as it exists or moves on from that point. The emphatic effect which this use of there evokes results possibly from the constituents being at the juncture of two events and in focused preposed position.

If one takes example (77), analysis shows that there we go was said by the sports announcer immediately after his comments describing the unspectacular semi-final tennis match at a point when the match took a turn in the opposite exciting direction. There, as a backward looking item, configures the termination of a boring game and signals the beginning of an exciting one, we refers to players, spectators and television announcer and go describes the way in which we moves on from that situational end-space. 
Similarly, there you have it in example (78) comes at the end of the article as the first line of the conclusion. There serves as a backward looking item marking the end of a discussion over what entails a good summer read for the author, you refers to the reader and have it implies the reader has all the author's information for good summer books. In the case of there you are (79), the word there serves as the backward looking item toward the discussion which has just transpired, and the you are can be interpreted as the speaker saying, 'I told you so' or 'you are, how I predicted you would be: you think I am mad.'

Analysis of example (80), repeated below as (81a), is more complex because at first glance there appears to be associating cataphorically with the PP, on that slimy table. However, there are problems with this simple analysis. First, it does not explain the behavior of there with regards to its preposed position which is primarily connective to the prior discourse. Second, this analysis falls into an erroneous assumption which posits a relationship between there and a PP which is not necessarily existent. One is reminded of early discussions on existential there in which there was thought to be referring to a PP as in the classic example: In the garden, there was a unicorn or There was a unicorn in the garden. This relationship was disproved when it was shown that there are cases of existential there with no locative constituents, which in turn, confirms the different functional roles of existential and locative there.

(81) a. 'A girl's blood, Mr. Tanaka?' [...] 'where we bring the fish?' [...] 'I'd say her blood will be the cleanest thing to hit this floor since you or I were born. Go ahead. Spit it out.' There I sat // on that slimy table, uncertain what to do.

[ Golden 1997: 15]

b. 'Go ahead. Spit it out.' I sat on that slimy table uncertain what to do.

c. 'Go ahead. Spit it out.' There I sat uncertain what to do.

d. 'Go ahead. Spit it out.' I sat there on that slimy table uncertain what to do.

Similarly, by submitting example (81a) to various syntactic tests and analyzing the resulting effects, it can be demonstrated that there does not function in relation to the post-verbal PP to particularize a location. First of all, the deletion of there in $(81 \mathrm{~b})$ shows that the passage is equally felicitous in terms of situating the young girl on the slimy table. This demonstrates that there is not 
obligatory to establish this locative connection, and hence, its function must be elsewhere. Second, the absence of there in (81b) also denotes a change in meaning which demonstrates that a function of there is to provide some kind of subjective meaning to the passage. Third, even the deletion of the post-verbal PP in (81c) does not alter the emphatic effect of the preposed constituents. This demonstrates once again that there does not function in relation to the post-verbal PP; rather it hints at some other relationship. Finally, a comparison of the use of there in (81a) and the frozen-state use of there in (81d) shows that both evoke similar subjective effects which are hard to qualify. In brief, the meaning evoked by there in (81a) does not derive from a relationship with the post-verbal PP but from some other association.

Indeed, inspection of the context, shows that the use of there in (81a) establishes a link with the previous discourse. The only possible locative referent in the preceding discourse is the phrase $a$ slimy table. However, this referential link is evaluated as highly unlikely due to textual distance; that is, it occurs ten paragraphs prior to there. Final analysis shows that this use of there conforms to the previous cases of there in (77-79) which occur at some situational end point. In example (81a), there occurs at the end of a lengthy debate over whether or not the young girl should spit on the fish-market floor and bring a curse to the fisherman. In sum, despite first impressions, there in (81a) functions in accordance to its status as a preposed item. Through its connective capacity, there provides the bridge which links an entity and activity to the terminal point of a previous situational event.

Thus, evidence at the phonological, semantic and discourse levels demonstrates that there can be actualized in two distinct ways within the discourse construction of preposing. Even though it is not clear whether there is a definitive phonological opposition of a stressed/unstressed there, there is, nonetheless a phonological opposition marked by a pause. With the particularizing locative use of there, a pause immediately follows there; whereas with the situational-outcome use of there, it comes after the informational unit and not after there. Semantically, the locative use of there denotes a particular space (it indicates where an event takes place); whereas, the situationaloutcome use evokes a more subjective type meaning. It evokes a focus on a situational outcome that is obtained by configuring a situational end-space within which is situated the way (verbal activity) an entity (pronominal) occupies or moves on from that terminal point. 


\subsubsection{More cases of unstressed there}

There are also other discourse segments which exhibit a phonological opposition between a stressed there which particularizes a location and an unstressed there evoking meaning that is semantically light. However, since there were insufficient tokens of the semantically light unstressed there in my corpus, analysis is limited.

The following example (82) is of a post-nominal stressed there that associates anaphorically with the referent expression Ain Charod. It, therefore, particularizes a space that is in opposition to any other space. In contrast, example (83a) from the Oxford English Dictionary (James et al. 1970: Vol. XI, 281) provides evidence of a post-nominal unstressed use of there. The meaning of the unstressed there does not appear contrastive; that is, it is not situating the pillow within another particular location as in example (83b). Furthermore, it produces an expressive effect which is absent with its non-use.

(82) [...] my son's colony; Ain Charod, \&they call it. My son has a quarter of a house $\leftarrow$ there, with his wife and children

[Golding 1939: 24]

(83) a. "Appended, unstressed, to the name of a person or thing to whose presence attention is called:

$[\ldots]$ There she lay,... her face upon the pillow there!" (my emphasis)

[OED, there, B.2]

b. There she lay,... her face upon the pillow there $\rightarrow$ at the end of the bed.!

Similarly, example (84a) below also has an unstressed use of there relative to the stressed pronoun you. Semantically, this unstressed there is not contrastive; that is, it is not denoting a space which is in opposition to any other space as is the stressed there in example (84b): 
(84) a. [...] I would never see her again, and grew so upset that one of the teachers, just before the beginning of the class, silenced everyone and said to me: 'You there! What's troubling you?'

[Golden 1997: 57]

b. You there! (I want you in that space and no other.)

According to the OED these cases of appended unstressed there call attention to the presence of a person or thing. This suggests that there may be associating with the nominal to configure space that is defined by the nominal and therefore calls attention to itself. This analysis does correspond to the intonation pattern of stress where the nominal is stressed relative to the unstressed there; furthermore, it is reminiscent of the phonological pattern of the frozen-state use of there where the verb is stressed and defines the space of a relative unstressed there.

Another possibility is that this use of an unstressed there is minimally defined; that is, its non-constructed open space is only defined as space outside of the speaker wherein is situated an entity. This last analysis may correspond to the following uses of unstressed there which are contextually defined only by the speaker who calls out to an entity outside his 'space':

(85) Hi there.

(86) Hey there little cat.

[advertisement on CBC television, 08/09/03]

In conclusion, even though there is insufficient data for a full analysis, these cases of there reveal that unstressed realizations of there do occur in other syntactic positions besides the preverbal position of inversion and in the verb + there construction. In addition, they show that there exhibits systematic patterns where some kind of phonological opposition corresponds to semantic distinctions associated with the use of there.

\subsubsection{Conclusion}

This section has provided evidence that there are semantically distinct phonological oppositions of there in different discourse constructions. In preposing, this opposition is 
phonologically signaled by a pause: when there particularizes space, the pause comes immediately after there, whereas when there configures a situational end-space, the pause comes post-verbally or after the object. In addition, there are other unstressed uses of there which can be defined as semantically light since their meaning is hard to ascertain. They are in opposition to usage evoking a space that is particularized and contrastive.

\subsection{The systemic nature of there}

Through a comparison of the different realizations of there within three discourse constructions, the systemic nature of there becomes apparent. The discourse constructions in question also contribute to propositional meaning and, therefore, impose limitations on the way there can be realized within their borders. This reveals that the existential use of there is only a single realization among several and occurs within the syntactic limitations of inversion. 


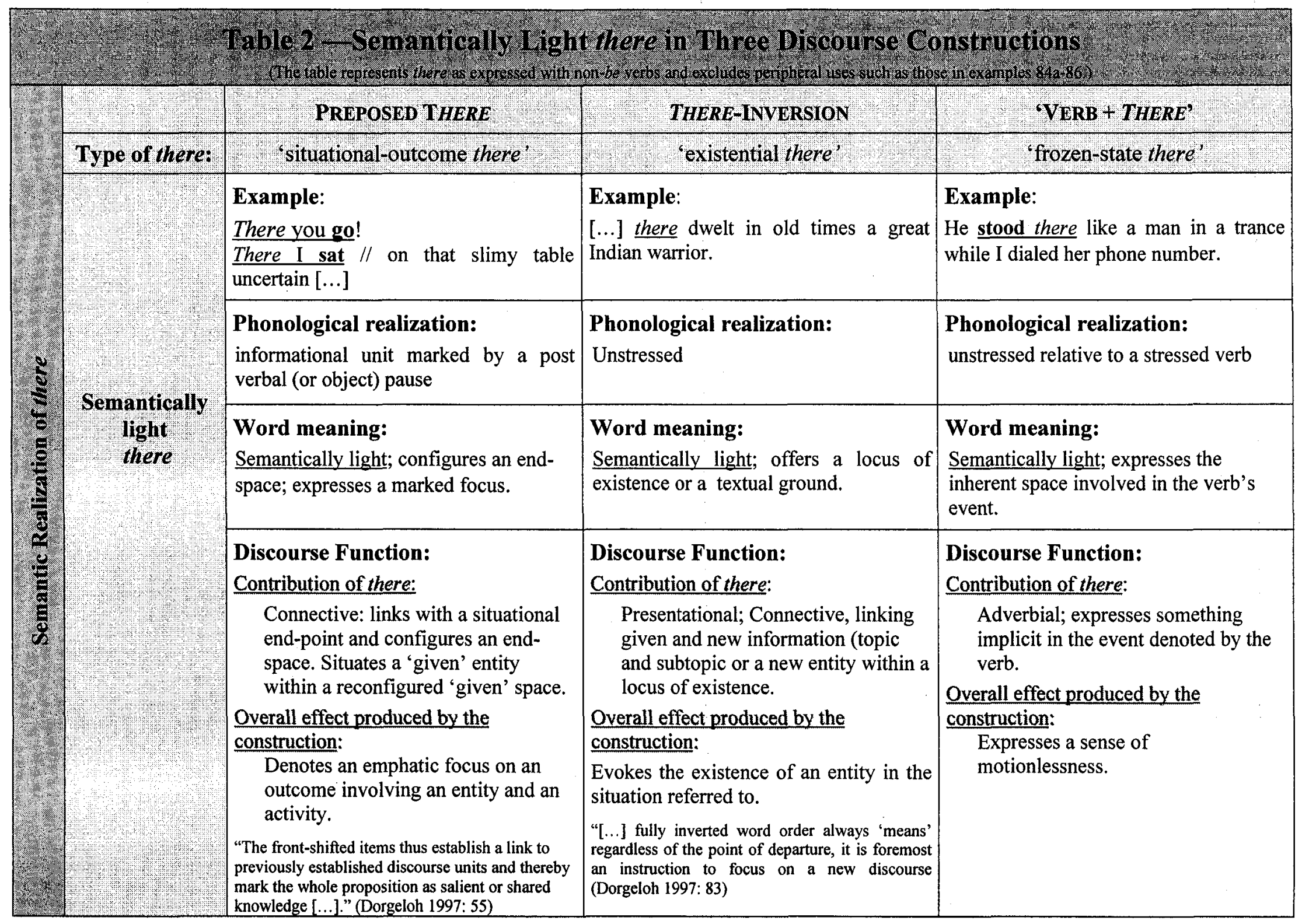




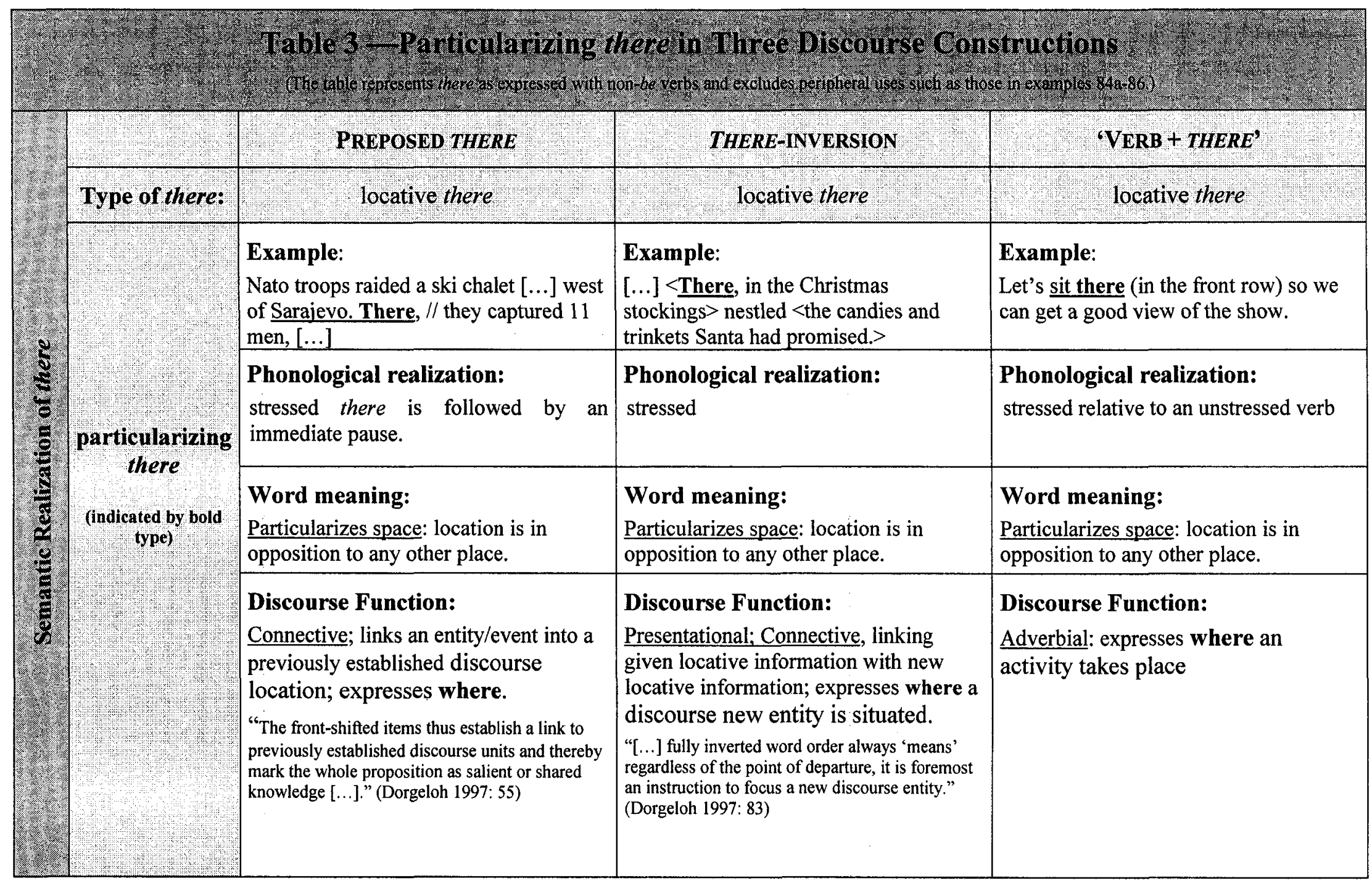


First of all, a comparison of Table 2 and Table 3 shows that in all three discourse constructions allow for two realizations of there. One is qualified as semantically light and the other as particularizing there. Furthermore, these meaning distinct uses of there are signaled by some kind of phonological opposition. In preposing, it is signaled by a post-there pause versus no postthere pause, and in inversion and the verb + there constructions, the opposition is marked by stressed versus unstressed there. What this reveals ultimately is that the existential and locative there opposition, once considered unique to the inversion construction, is characteristic of the meaning potential of there which allows for two meaning exploitations of there within a given discourse construction.

Second, a comparison across both tables reveals those features which characterize the opposing uses of there. All the locative uses of there across Table 3 are stressed and particularize space expressing where an entity/activity is situated. In contrast, Table 2 reveals that the situational-outcome, the existential, and the frozen-state uses of there are all semantically light and participate with the discourse construction to evoke some sense of how an activity takes place (for the existential there construction see Birner 1996: 119; Levin \& Rappaport Hovav 1995: 258). In addition, they are all phonologically distinct from the locative use of there. Even though the phonological distinction is not marked clearly in terms of a stressed / unstressed there opposition, "Givón (1993) reminds us [that] membership in natural categories is not determined by rigid adherence to all criteria. Rather, membership is determined by a cluster of criteria" (Celce-Murcia \& Larsen-Freeman 1999: 42). As such, the uses of semantically light there in Table 2 share sufficient features to be considered members of a same class of non-locative uses. In turn, the existential use of there can only be considered one realization of a semantically light there occurring within the parameters of a single discourse construction.

A third comparison of the tables shows that each discourse construction functions distinctly and imposes limitations on how there can function within its borders. As Ford (1993: 146) states, adverbials "tend to work more locally in narrowing main clause meaning without creating links or shift points in a larger discourse pattern" (Dorgeloh 1997:58). Indeed, both realizations of there occurring in the verb + there construction function locally in relationship with the verb. More specifically, the locative use of there situates the verbal activity within another particular space; 
whereas, the frozen-state use of there situates an entity within the very space involved in the verb's event. In both there-inversion and preposing, there is positioned clause-initially and, therefore, functions across sentence borders, providing links with units of information. What distinguishes these two constructions at a functional level is the type of information felicitously allowed as postthere constituents. The constituents in inversion are marked as discourse 'new' information, whereas in preposing, the constituents are marked as "salient or shared knowledge" (Dorgeloh 1997: 55). This difference in information status is evidenced in the propensity of pronouns (they tend to refer to discourse old entities) that occur as post-there constituents in preposing especially so with the 'situational-outcome' use of there (see examples $77-80$ ). This reveals once again that there can only function existentially within the confines of the inversion construction. Hence, 'existential there' is only a single realization derived from the meaning potential of there.

In sum, the different realizations of there across discourse constructions reflect patterns of a system which ultimately reveals that the existential use of there is but one realization of the underlying meaning potential of there.

\subsection{The Semantics of there}

It is increasingly being recognized in current linguistic research "that syntactic properties of phrases reflect, in large part, the meanings of the words that head them" and that "subtle differences in word meaning correlate with otherwise puzzling differences in the syntactic structures that the word can appear in" (Levin \& Pinker 1992: 3). Though this perspective may appear new, it forms the basis of the Guillaumian theory that views actualized meanings as the result of the multi-level interactions of a word's potential meaning. It is only from such a meaning perspective that a unified account of there can ultimately be proposed.

\subsubsection{The VERB + THERE construction: non-be verbs versus be verbs}

In the literature, existential there sentences are sometimes re-divided into two constructions: the presentational there construction with non-be verbs, and the existential there construction with 
the verb be. From a practical standpoint, discussion here has followed the same division. The preceding sections dealt with those occurrences of there with non-be verbs in the various discourse constructions because they exhibit regular patterns of intonation and meaning. The sections that follow will deal with interactions of there and the verb be because they can express various combinations and gradations of meaning that sometimes neutralize stress.

In terms of statistics, a comparison of non-be and $b e$ verbs within the verb + there construction shows that the phonological realization of there is more clearly identifiable in tokens with non-be verbs. That is, of the 54 tokens with non-be verbs, 37 were identified as unstressed actualizations of there evoking motionlessness, 14 were identified as stressed evoking a particular place, and only 3 tokens were considered ambiguous since both stressed and unstressed realizations were possible in the context.

In contrast, many more tokens with the verb be in the verb + there segment were qualified as ambiguous. Of the 53 tokens with the verb $b e, 16$ were identified as unstressed there, 10 were identified as stressed there, and the remaining 27 were identified as ambiguous. Included as ambiguous were those cases in which both a stressed there and unstressed there were possible, or in which the meaning was a fusion of locative, presence, existence, or some other sense related to the notion of location, and where stress was neutralized.

The distinct behavior of non-be verbs and $b e$-verbs does not contradict the previous findings. Instead, it confirms that a discussion divided on these lines is appropriate. Moreover, the distinct interactions of there, be and local contexts allow for a fusion of meaning where location, presence, and existence can all intertwine, which shows that the notion of existence is closely linked to the concept of space.

\subsection{2 ' $b e$ ' + there evoking presence: another link to the existential use of there}

As it has been observed in the literature, 'locative' there can denote 'existence,' a sense which is also evoked by the existential use of there (Breivik 1981; Quirk et al. 1985). This sense 
occurs via the interactions of the verb be and there in the same discourse construction that evokes the 'frozen-state' sense of there: VERB + THERE. The systematic behavior of be and there within this construction provides more evidence of a link between the existential and locative use of there.

First of all, there are phonological minimal pairs which correspond to meaning differences and which follow the same prosodic pattern as non-be verbs (section 4.2.2):

International Snowmobiler's Show. $\leftarrow$ [...] Oh! Try Blair Morgan [...] Snowmobile racers from Canada and the USA will all be $\leftarrow$ there. If you want to meet and see the most influential players in snowmobiling, be there!

[advertisement, Supertrax, Fall 1998, p. 22-23]

In the first occurrence of be there in (87), there evokes a 'particular' place, an International Snowmobiler's Show, and it is stressed relative to an unstressed verb be (like sit there of example 62). In contrast, the second occurrence of there evokes 'presence' and is unstressed relative to a stressed be (like sit there of example 62).

Second, tokens which express 'presence' can occur in contexts which have no locative information at all, which is a feature of the unstressed uses of there (including the existential use of there, see Table 2):

(88) For more than 49 years, we've been there for the good times and the hard times [...]

[television advertisement, Sun Life, 29/07/00]

(89) He was always there when I needed him.

In such cases, there does not evoke a particular location, but rather a variable one defined by a relation to a particular person or event. In (88), for instance, there evokes 'wherever the insurance companies' clients have needed them.' The overall effect of such a construction is to evoke presence or accompaniment, i.e. someone or something being in the location defined by the other person or thing. 
Thirdly, the high number of ambiguous tokens from written sources shows just how closely the notions of space and presence are related. For example in (90) below, two interpretations are felicitous in the context; there can either denote a 'particular' space or evoke 'presence':

(90) a. 'This pot is cracked. Look.' 'It isn't cracked,' I said. 'That line has always been there.'

b. That line has always been there.

[Golden 1997: 17]

One might think that the mention of a location in the context would favor a locative interpretation and reduce the number of tokens judged ambiguous. However, as the following token demonstrates, the presence of locative information does not determine the interpretation of there:

(91) When the Olympic Games begin, $\mathrm{CBC}$ will be there. [television advertisement, $\mathrm{CBC}, 29 / 07 / 00]$

In this example from an oral source, be was stressed relative to the unstressed there indicating that the intended meaning was that 'the $\mathrm{CBC}$ would be present at the Olympics.' These are again the same arguments that reoccur with all the uses of unstressed there: it is not the presence or absence of a PP that determines the interpretation of an unstressed there.

The pertinence of the ambiguous cases involving the interactions of be and there is that they show how closely the notions of 'space' and 'existence' are intertwined. With a simple 'flip of the phonological switch of stress,' there can denote a particular space, or on the other hand, evoke a variable situationally dependent space, as in (91) in a construction denoting presence and which is semantically very close to the notion of 'existence.'

In brief, this use of be + there construction provides more evidence that the various uses of there are all derived from the same potential meaning. Not only is there a phonological minimal pair that corresponds to meaning differences, but unstressed there shares features of the other unstressed uses and it evokes meanings of 'presence' and 'existence,' manifesting a semantic link to the existential use of there. 


\subsubsection{Simple forms of be + there: the neutralization of meaning and stress}

The remaining tokens of be + there involve simple forms of the verb be. These cases are more problematic for two reasons. First, there can evoke a variety of meanings and meaning combinations depending on the context, and second, stress appears neutralized in many cases, (at a level between an unstressed or stressed there). Nevertheless, the cases of there in the context of simple forms of be further confirm the close semantic ties that exist between notions of space and existence and therefore, between the existential and locative uses of there.

The following tokens show a gradation of meanings that there can evoke in the context of simple forms of the verb be. These meanings range from 'pure' location in (92), to existence in (93), to availability fused with spatio-temporal meaning in (94), to not having arrived at a certain level of human existence in (96):

(92) EVOKES PARTICULAR PLACE (BORDEAUX):

I wanted her to tell me something about Bordeaux, $\leftarrow$ but she was too preoccupied. [...] The government and its agencies were $\leftarrow$ there. There had been a bombing, the Germans had known precisely in which buildings the ministries were housed.

(The items in italics confirm a locative reading)

[Döblin 1992: 158]

(93) EXISTENCE:

Aside from his climbing, Mallory's place in history is secure, if only for his memorable answer to the question of why he wanted to climb the world's highest peak: 'Because it is there.'

[Howland, D. "Climbers Say Body Found on Everest." Associated Press. 05/03/99, daily news.yahoo.com]

(94) MENTAL PRESENCE AT A SPATIO-TEMPORAL JUNCTURE

"Could you read that again? I wasn't there."

[comment expressing inattention made by $\mathrm{D}$. Mackin at a meeting $1 / 06 / 99]$ 
(95)

PRESENCE/AVAILABILITY FUSED WITH SPATIO-TEMPORAL MEANING:

'Of course I missed you,' his father said. 'I needed to hear that,' Jeff said. 'As soon as I touched his hands, I knew those were the hands that I had dreamed would hold me, tickle me, and wrap around mine, to show me how to swing a bat, how to catch a ball.' But until that moment in 1989, those hands were never there for Jeff.

[Welch, "Restoration," Focus on the Family, June 1998, p. 6-7]

EVOKES NOT HAVING ARRIVED AT A CERTAIN LEVEL OF EXISTENCE:

We call that consciousness. $\leftarrow$ Deep Blue [chess computer] is not $\leftarrow$ there yet, though one day we will be tempted to ask him. In the meantime, $h e$ 's done alchemy, turning quantity into quality. That in itself is scary.

[Krauthammer, C., “Deep Blue Funk,” Time, 26/02/96]

Even though these examples do not show the entire scope of meanings there can contribute to evoking (when preceded by a simple form of be), they are representative and sufficiently demonstrate:

1.) At a semantic level,

$>$ that a variety of senses can be combined to evoke meaning. Many tokens in the corpus combined two to three of the following senses: location, spatio-temporal space, presence, existence, availability, and arrival.

that context and pragmatic associations modulate the meaning of there. For example in (92), a locative interpretation is confirmed by bombings and the phrase known precisely in which buildings. Without these constituents, the interpretation of there would be ambiguous. In (93), context and pragmatic associations contribute to the interpretation of 'existence.' Similarly, (94) lends itself to an interpretation of 'inattention' or 'mental absence' at the spatio-temporal juncture of a discussion. Context and pragmatic associations with world knowledge also contribute to the interpretation of there in (95), which is a mix of senses (the constituents in the examples which modulate or confirm a specific interpretation of there are italicized.) 
Finally in (96), even though there associates with the word consciousness, it is through associations of world knowledge that 'human existence' can be inferred because consciousness is an attribute of humans.

$>$ that the assertion of the existence or presence of an object is equated with the assertion of a spatio-temporal location for that object (Hannay 1985: 24).

2.) At the syntactic level, that meanings of presence and existence occur in the combined presence of be and there.

At a phonological level, the role of stress is not fully clear. The above examples show that stress does not seem to follow the same pattern previously exhibited by there. For example in (93) and (94), stress appears to be neutralized (neither stressed or unstressed). In examples (93) and (94), it may be that stress is neutralized because the meaning of there combines the sense of location and presence/existence which normally correspond to opposing patterns of stress.

The following two examples also suggest that the phonological realizations of there are meaning related. Negations that evoked the 'non-presence' or the 'non-existence' of an item or entity all stress the simple forms of be relative to an unstressed there:

(97) NON-PRESENCE EMBEDDED WITH LOCATION:

In a car you might as well be a cabdriver, unfamiliar with English, for all the kids will notice you. They're irrepressible, so intent on conducting their business they convince themselves you aren't there.

[Carlson, M., "Here's a Precious Moment Kid," Time, 22/09/97]

(98) NON-EXISTENCE EMBEDDED IN LOCATION:

The emerging investment markets have drawn most of the attention in recent years partly because of the rates of return sometimes available and partly because they simply weren't there before.

[“Global Agenda," Time, 4/03/96] 
In conclusion, even though the interactions of simple forms of be and there demonstrate some phonological differences, at the semantic level, they confirm that the notions of presence and existence are embedded in the meaning of there space. This gives credence to the classical dictum that "whatever is, is somewhere; what is nowhere, is nothing" (Kahn 1966: 258).

\subsubsection{Other cases of 'locative' there and be expressing existence}

The following examples have occurrences of there that would normally be qualified as 'locative.' Nevertheless, both questions express 'existence,' confirming that notions of space and existence are closely equated:

(99) Section title appearing above the article title: Space

Article title: Is Someone Out There?

Subtitle: Two planets are found orbiting faraway stars-and one just may have a suitable climate for alien life.

[Lemonick, M., "Is Someone Out There?," Time, 29/01/96]

(100) Section title in a book next to a photograph of a starry sky:

Is Anyone Out There?

[Funston 1996: 46]

What is being queried is the existence of entities in 'outer-space' which is inferable through contextual and pragmatic associations. Phonologically, these cases reflect the same pattern as other uses of unstressed there (relative to other constituents) which is opposed to a stressed there and a meaning difference. In (99) and (100), the location referred to is the broad expanse of outer space whose contents are unknown to the speaker, and so the effect of asking whether anyone is in this location is pragmatically equivalent to a question about existence. This can be compared to (101) where there denotes a specific place:

(101) I want you to put that out there $\rightarrow$ on the deck. 
This particular use of a so called 'locative' there reaffirms the close equation there is of existence and location.

\subsubsection{The meaning of the existential use of there and its relationship to SAI}

This section examines the question of why there can undergo subject-auxiliary inversion in its existential use but not in its locative use:

(102) a. There is a God.

b. Is there a God?

(103) a. There at the corner was Bill.

b. *Was there at the corner Bill?

By virtue of being a space defined in opposition to here, which implicitly evokes the existence of the speaker, there can denote a 'locus of existence' to which things can be denied or allowed access. It is this meaning that authorizes the existential use of there to undergo subjectauxiliary inversion. Questions in English begin with the item being questioned (Méry 1994: 17-18), as illustrated in (102b). A question beginning with be therefore queries the existence of something. It follows logically that any locative adverbial modifying the verb be can only evoke a locus of existence. This explains the possibility of there's use in (102) above, in contrast to its impossibility in (103).

\subsubsection{The semantics of the potential meaning of there}

Sufficient evidence has been provided in this study to demonstrate that the existential and locative uses of there (as well as the newly discovered uses) all share the same underlying MEANING POTENTIAL of adverbial there. More generally, it has been shown that the various manifestations of there are systematic exploitations of this potential meaning, which is evidenced in the systematic use of supra-segmental devices (stress and pause) to signal the meanings that are realized in the 
various syntactic positions there can occur in. The potential meaning inherent to all the various actualized meanings of there is characterized by:

1.) A BASIC MEANING: the potential meaning of there can be defined as an unconfigured open space represented as not containing the speaker. This is due to its space being defined as a complement to the space denoted by here, which encompasses the speaker. Since there evokes pure space, it can serve as a locus of existence for any entity.

2.) AN ASSOCIATIVE POTENTIAL: its inherent associative potential provides there with the capacity to interact with other constituents in the world of discourse (cotextual, situational, pragmatic, discourse level) that configure its undefined open space.

3.) A CONNECTIVE CAPACITY: the inherent connective capacity of there allows it to serve as a situator, situating entities and events within its reconfigured space and allows it to connect given and new information at discourse or referential levels.

4.) FACTORS WHICH MODULATE THE POTENTIAL MEANING: Intonational devices (pause and stress), discourse structures and context modulate this meaning potential (Bolinger 1972: 633 ) into the various realizations in actual discourse. These realizations range from:

$>$ LOCATIVE USES to evoke particular physical location, temporal space, narrative space, etc. These uses express where an activity or event is situated

$>$ SiTUATIONAL-OUTCOME USES to denote the situation defined by some newlyterminated event or discussion.

EXISTENTIAL USES to denote a locus of existence or textual ground. The construction with this use of there expresses the simple occupation of an existential locus/textual ground. 
FROZEN-STATE USES to denote the space minimally required by the verb's event. The construction with this use of there expresses how an entity occupies. the space defined by the verbal event.

$>$ VARIABLE, SITUATIONALLY-DEFINED SPACE to evoke presence, availability, existence, as well as various combinations of meaning.

This is not considered an exhaustive listing of the possible realizations of there. Nonetheless, it provides a striking example of how a potential in tongue is a tool which can be applied to a wide variety of uses in discourse. 


\section{CHAPTER 5}

\section{CONCLUSION}

This study was based on a simple problem questioning whether the existential and locative use of there were inherently the same word or whether they were homophones with little in common but a shared graphic sign. Sufficient evidence on both sides of the equation has kept the problem at a standstill since its inception in the 1970's.

Underlying the problem, and also masking the solution, was an unbalanced interest in the existential use of there which, despite the many contributions of research, kept the locative use of there out of focus. It was either eliminated from studies or measured against the standard of the existential use, to which it could never fully conform. As a result, this study determined that locative there needed focused attention to understand how it behaved and expressed meaning in and of itself. In this study, it was thought that such an understanding, in turn, would provide parallels with the existential use of there, if there were any. This, in fact, proved to be the case.

Compounding the problem of there were the underlying and unwarranted assumptions about the way locative there is thought to function. First, it is widely assumed that the locative use of there functions by substitution. Second, there exists a referring/non-referring dichotomy in the literature which is limited in its ability to explain the function of there. Third, it is also assumed that there's phonological attributes are comparable to those of other pro-forms. A set of assumptions is adequate only in so far as it can explain the data; unfortunately, in the case of there these assumptions fail at such an attempt.

It has been demonstrated in this study that locative there functions by associating with other contextual constituents, rather than by substitution. The notion of associative function, as opposed 
to that of referring has been shown to better reflect the associations which the various uses of there can establish at both referential and textual levels. It has also been shown that stress neither signals anaphoric or cataphoric relations nor is related to given or new information as is the case for pronouns. In the case of there, stress seems rather to function contrastively, signaling differences of meaning.

A detailed analysis of the corpus has shown, in light of these assumptions, that the existential use of there has the same potential meaning as the locative use of there. There are a number of parallels which confirm such a conclusion, some of which are:

First, the associative potential and connective capacity of the locative use of there parallel the functional capacities of the existential use of there.

$>$ Second, there are phonological minimal pairs in the verb + there construction which are comparable to the 'locative there/existential there' minimal pair of the inversion construction. These 'new' minimal pairs correspond to meaning differences in which a stressed locative use of there configures a particular space, whereas an unstressed there relative to a stressed verb evokes the space inherent in the verb's event. This 'new' minimal pair seems to indicate that stress is contrastive in the case of there.

Third, at a semantic level there has a capacity to be used in constructions which express presence or existence. This sense is evoked not only by the existential use of there but also by the combined interactions of context, the verb be and there in the verb + there construction. It has also been shown to occur with other uses of 'locative' there.

In order to arrive at a unified account of there, there were two major hurdles to overcome: explanations for the phonological difference between the existential and locative use of there were necessary, as they were for the unusual behavior of the existential use of there in SAI. Stress has been shown in certain cases to be contrastive and therefore meaning-based. While further research must be done in this area, it is at least possible now to offer a plausible hypothesis as to why there does not carry stress in its existential use. The participation of there in SAI has also been explained 
in the light of meaning: as a fronted item evoking a locus of existence, the type of meaning expressed in the existential use of there authorizes it to undergo question formation wherein the existence of an entity is questioned.

In conclusion, all the uses of there can be derived from one underlying potential meaning that signifies an undefined open space. Its actualization in the realm of discourse is modulated by context, phonological markers and the limitations inherent in the syntactic position of a given discourse construction. When there associates with other elements at the referential level, it configures a particular space in which an entity or event is situated; when associations are made at other levels, there is no reference to a particular physical space. This causes there to appear "semantically light," but, as we have seen, it continues to be the same word, only applied to various domains (mental, situational, textual) or defined by different parameters (inherency to a verbal event, relation to a person or event, use to evoke an existential locus, etc.). This is the sign of a very abstract and powerful potential, capable of uses ranging from the denotation of a particular location all the way to the evoking of a locus of existence. 


\section{REFERENCES}

This bibliography contains not only references quoted in this thesis but those sources that have helped shape and mold the direction this thesis has finally taken. Most attempts at problemsolving are filled with dead-ends and back-tracking. However, it is by examining the different venues previously taken that new directions are discovered and pursued.

ABBOTT, B. (1997). Definiteness and existentials. Language, 73 (1), 103-108.

AISSEN, J. (1975). Presentational there insertion : A cyclic root transformation. Papers from the Regional Meeting Chicago Linguistic Society, 11, 1-14.

ALLAN, K. (1971). A note on the source of there in existential sentences. Foundations of Language, 7, 1-18.

ALLAN, K. (1972). In reply to there1 there2. Journal of Linguistics, 8, 119-124.

ALLERTON, D. J., (1980). Grammatical subject as a psycholinguistic category. Transactions of the Philogical Society, 62-80.

ALLERTON, D. J., \& CRUTTENDEN, A. (1974). English sentence adverbials: Their syntax and their intonation in British English. Lingua, 27, 1-29. 
ALLERTON, D. J., \& CRUTTENDEN, A. (1979). Three reasons for accenting a definite subject. Journal of Linguistics, 15, 49-53.

ALLSOP, J. (1992). Students' English Grammar. New York: Prentice Hall.

ANIYA, S. (1992). The semantics and the syntax of the existential there-construction. Linguistic Analysis, 22 (3-4), 154-184.

BARDOVI-HARLIG, K. (1983). Pronouns: When given and new coincide. Papers from the 19th Regional Meeting, Chicago Linguistic Society, 15-26.

BARNHART, R. K. (1988). The Barnhart Dictionary of Etymology. New York: HW Wilson.

BIRNER, B. (1994). Information status and word order. Language, 70 (2), 233-259.

BIRNER, B. (1996). The Discourse Function of Inversion in English. New York: Garland.

BIRNER, B., \& WARD, G. (1993). There-sentences and inversion as distinct constructions: A functional account. Proceedings of the 19th Annual Meeting of the Berkeley Linguistics Society, 27-39.

BIRNER, B., \& WARD, G. (1998). Information Status and Noncanonical Word Order in English. Philadelphia: John Benjamins. 
BOLINGER, D. (1961). Contrastive accent and contrastive stress. Language, 37, 83-96.

BOLINGER, D. (1977). Meaning and Form. New York: Longman.

BOSCH, P. (1983). Agreement and Anaphora. New York: Academic Press.

BOSCH, P. (1987). Pronouns under control? A reply to Liliane Tasmowski and Paul Verluyten. Journal of Semantics, 5, 65-78.

BREIVIK, L. E. (1977). A note on the genesis of existential there. English Studies, 58 (4), 334348.

BREIVIK, L. E. (1979). [Review of Jenkins 1975 \& Erdmann 1976]. English Studies, 60, 216230.

BREIVIK, L. E. (1981). On the interpretation of existential there. Language, 57 (1), 1-25.

BREIVIK, L. E. (1983a). Existential There: A Synchronic and Diachronic Study. (Studia Anglistica Norvegica 2). Bergen: Department of English.

BREIVIK, L. E. (1983b). On the use and non-use of existential there. [Review of the book Existential Sentences in English]. Lingua, 61, 353-368. 
BREIVIK, L. E. (1983c). On the use and non-use of existential there in present day English. Lingua, 61 (4), 353-368.

BRESNAN, J. (1994). Locative inversion and the architecture of universal grammar. Language, 70 (1), $72-131$.

BROWN, G. (1884). A Grammar of English Grammars. New York: William Wood.

BROWN, C. H. (1985). Polysemy, overt marking and function words. Language Sciences, 7 (62), 283-332.

BRYANT, M. M. (1978). [Review of There Sentences in English]. Word, 9 (3), 264-269.

BURCHFIELD, R. W. (1996). The New Fowler's Modern English Usage. Oxford: Clarendon Press.

CADIOT, P. (1987). De quoi ça parle? a propos de la référence de ça, pronom-sujet. Le Français Moderne, 55, 174-192.

CARTER, D. M. (1990). Control issues in anaphor resolution. Journal of Semantics, 7 (4), 435454.

CELCE-MURCIA, M. (1990). Discourse analysis and grammar instruction. Annual Review of Applied Linguistics, 11, 135-151. 
CELCE-MURCIA, M., \& LARSEN-FREEMAN, D. (1999). The Grammar Book. Heinle \& Heinle.

CERVONI, J. (1990). La partie du discours nommée adverbe. Langue Française, 88, 5-11.

CHAFE, W. L. (1976). Givenness, contrastiveness, definiteness, subjects, topics and point of view. In: Ch. N. Li (Ed.), Subject and Topic. (pp. 25-55). New York: Academic Press.

CHEN, R. (1990). English demonstratives: A case of semantic expansion. Language Sciences, 12 $(2 / 3), 139-153$.

CORNISH, F. (1987). Anaphoric pronouns: Under linguistic control or signalling particular discourse representations?. Journal of Semantics, 5, 233-260.

DENNY, J. P. (1978). Locating the universals in lexical systems for spatial deixis. Papers From the Parasession on the Lexicon, Chicago Linguistic Society, 71-84.

DORGELOH, H. (1997). Inversion in modern English: Form and function. Philadelphia: John Benjamins.

DUFFLEY, P. (1988). The meaning of $-s$ ending in the English verb and the significance of its absence. Paper presented at the $5^{\mathrm{e}}$ colloque international de psychoméchanique du langage.

DUFFLEY, P. (1999). [Review of H. DORGELOH, Inversion in modern English.]. Word, 50, 2, 232-237. 
ENNS, P.J. (1994). A Psychomechanical Analysis of the English Infinitive in Modern-day Usage Where it is Preceded by the Following Wh-Words: Who, What, Where, Why, Which and How. Quebec: Faculté des Etudes Superieures Université Laval.

ERDMANN, P. (1976). There Sentences in English: A Relational Study Based on a Corpus of Written Texts. Munich: Tuduv.

ERDMANN, P. (1990). Discourse and Grammar. Tübingen: Niemeyer.

FEUILLET, J. (1990). Structuration de la deixis spatiale. In: M. Morel \& L. Danon-Boileau (Eds.), La deixis, (pp. 233-244). Paris: Presses Universitaires de France.

FIRBAS, J. (1966). Non-thematic subjects in contemporary English. Travaux Linguistiques de Prague, 2, 239-236.

FIRBAS, J. (1992). Functional Sentence Perspective in Written and Spoken Communication. Cambridge: Cambridge University Press.

FOWLER, H. W. (1970). A Dictionary of Modern English Usage. Oxford: Clarendon Press.

FRASER, T., \& JOLY, A. (1979). Le système de la deixis: Esquisse d'une théorie d'expression en anglais. Modèles Linguistiques, 1 (2), 97-157.

FRASER, T., \& JOLY, A. (1980). Le système de la deixis (2): Endophore et cohésion discursive en anglais. Modèles Linguistiques, 2 (2), 22-49. 
FUNK \& WAGNALLS. (1961). Britannica World Language Dictionary, (Vol. I-Vol. II). New York: Funk \& Wagnalls.

GARROD, S. C., \& SANFORD, A. J. (1988). Discourse models as interfaces between language and the spatial world. Journal of Semantics, 6 (2), 147-160.

GIVON, T. (Ed.). (1979). Syntax and Semantics (12). New York: Academic Press.

GIVON, T. (Ed.). (1983). Topic Continuity in Discourse: A Quantitative Cross-Language Study. Philadelphia: John Benjamins.

GIVON, T. (1993). English Grammar, (Vol. I \& II). Philadelphia: John Benjamins.

GORDON, P. C., GROSZ, B. J., \& GILLIOM, L.A. (1993). Pronouns, names and centering of attention in discourse. Cognitive Science, 17, 311-347.

GORDON, P., \& SCEARCE, K. (1995). Pronominalization and discourse coherence, discourse structure and pronoun interpretation. Memory and Cognition, 23 (3), 313-323.

GRAGG, G. B. (1978). Redundancy and polysemy: Reflections on a point of departure for lexicology. Papers From the Parasession on the Lexicon, Chicago Linguistic Society, 7184.

GUIMIER, C. (1986). Syntaxe de l'adverbe anglais. Lille: Presses Universitaires de Lille. 
HAIMAN, J. (1986). [Review of Existential there : A synchronic and diachronic study]. The Canadian Journal of Linguistics, 31 (1), 88-91.

HALLIDAY, M.A.K. (1985). An Introduction to Functional Grammar. London: Edward Arnold.

HANNAY, M. (1985). English Existentials in Functional Grammar. Dordrecht, Holland: Foris Publications.

HAUSSER, R. R. (1979). How do pronouns denote? Syntax and Semantics, 10, 93-139.

HEESCHEN, V. (1982). Some systems of spatial deixis in Papuan languages. In: J. Weissenborn \& W. Klein (Eds.), Here and there: cross-linguistic studies on deixis and demonstration (pp. 81-109), (Pragmatics Beyond, III). Amsterdam: John Benjamins.

HILL, C. (1982). Up/down, front/back, left/right: A contrastive study of Hausa and English. In: J. Weissenborn \& W. Klein (Eds.), Here and There: Cross-linguistic Studies on Deixis and Demonstration (pp. 11-42), (Pragmatics Beyond, III). Amsterdam: John Benjamins.

HIRTLE, W. H. (s.d.). The Challenge of Polysemy: Manuscript.

HIRTLE, W. H. (1982). Number and Inner Space. A Study of Grammatical Number in English. Quebec: Presse de l'Université Laval.

HIRTLE, W. H. (1985). Linguistics and the dimensions of Language. Lingua, 67, 65-83. 
HIRTLE, W .H. (1989). Gustave Guillaume: comment discerner l'invisible. Actes de Langue Française et de Linguistique, 2, 61-71.

HIRTLE, W. H. (1994). Meaning and referent: For a linguistic approach. Word, 45, 2, 103-117.

HOGG, R. M. (1992). The Cambridge History of the English Language (I \& II). Cambridge: Cambridge University Press.

HUANG, S. F. (1975). A Study of Adverbs. The Hague: Mouton.

HUCKIN, T., \& HUTZ-PESANTE, L. (1988). Existential there. Written Communication, 5 (3), 368-391.

HUFFMAN, A. (1999). The Function of Full-verb Inversion in English. Paper presented at the $44^{\text {th }}$ International Linguistics Association Annual Conference, New York, April 1999.

JACKENDOFF, R. (1993). Semantic Structures. Cambridge, Massachusetts: MIT Press.

JACOBSEN, B. (1986). [Review of the book Existential there: a synchronic and diachronic study]. English Studies, 67 (3), 250-262.

JACOBSON, S. (1978). On the Use, Meaning, Syntax of English Preverbal Adverbs. Stockholm: Almqvist \& Wiksell. 
JACOBSON, S. (1981). Preverbal Adverbs and Auxiliaries. Stockholm: Almqvist \& Wiksell.

JACOBSON, S. (1964). Adverbial Positions in English. Stockholm: Studentbok.

JACOBSSON, B. (1951). Inversion in English with Special Reference to the Early Modern English Period. Uppsala.

JACOBSSON, B. (1977). Adverbs, prepositions, and conjunctions in English: A study in gradience. Studia Linguistica, 31, 38-64.

JAMES, A. B. et al. (1970). The Oxford English Dictionary, (Vol.V \& XI). London: Oxford University Press.

JARANOWSKI, Z. (1987). Definites, presupposition, and anaphoricity in there-sentences and adjectival predicate constructions. Papers and Studies in Contrastive Linguistics, 14, 1782.

JENKINS, L. (1975). The English Existential. Tübingen: Max Niemeyer Verlag.

JESPERSEN, O. (1909-1949). A Modern English Grammar on Historical Principles. London: Allen and Unwin.

KAHN, C. H. (1966). The Greek verb to be and the concept of being. Foundations of Language, 2, 245-246. 
KIMBALL, J. P. (1973). The grammar of existence. Papers from the Ninth Regional Meeting Chicago Linguistic Society, 9, 262-270.

KLEIBER, G. (1983). Article défini, théorie de la localisation et présupposition existentielle. Langue Française, 57, 87-105.

KLEIBER, G. (1990). Anaphore-deixis: Deux approches concurrentes. In: M. Morel \& L. DanonBoileau (Eds.), La Deixis (pp. 613-624). Paris: Presses Universitaires de France.

KLEIBER, G. (1991). Celui-ci/là ou comment montrer du nouveau avec du déjà connu. Revue Québécoise de Linguistique, 21 (1), 123-169.

KLEIBER, G. (1993). L'espace d'ICI: Sur la pragma-sémantique des adverbes spatiaux. Le cas $d$ 'il fait chaud ici. Cahiers de Linguistique Française, 14, 85-104.

KLEIBER, G. (1994a). Contexte, interprétation et mémoire: Approche standard vs approche cognitive. Langue Française, 103, 9-22.

KLEIBER, G. (1994b). Référence pronominale: comment analyser le pronom Il?. Lalies-actes des sessions de linguistique et de littérature, 13, 79-141.

KLEIN, E. (1967). A Comprehensive Etymological Dictionary of the English Language, (Vol.II). New York: Elsevier.

KLEIN, U. F. G. (1991). Focus: An idea in motion. Journal of Semantics, 8 (1-2), 71-90. 
KOLAR, S. (1975). Aspects of polyfunctionality in English sentence adverbs. Philologica Pragensia, 18, 222-227.

KRUISINGA, E. \& ERADES, P. (1953). An English Grammar. $7^{\text {th }}$ edn. Vol I, Part I, Groningen: Noordhoff.

KUNO, S. (1971). The position of locatives in existential sentences. Linguistic Inquiry, 2 (3), 333378.

LANGACKER, R. W. (1988). [Review of the book Women, fire, and dangerous things: what categories reveal about the mind]. Language, 64 (1), 384-395.

LANNON, J. (1982). Technical Writing (2nd ed). Boston: Little Brown.

LAUGHREN, M. (1994). [Review of the book Lexical and conceptual semantics]. Language, 70 (3), 546-552.

LEGGET, G., MEAD, C.D., \& KRAMER, M. G. (1991). Prentice Hall Handbook for Writers. New York: Prentice Hall.

LEVIN, B. (1993). English Verb Classes and Alternations: A Preliminary Investigation. Chicago: University of Chicago Press.

LEVIN, B., PINKER, S. (Eds.). (1992). Lexical and Conceptual Semantics. Cambridge, Mass: Blackwell. 
LEVIN, B., \& RAPPAPORT HOVAV, M. (1995). Unaccusativity: At the Syntax-Semantics Interface. Cambridge, Mass: MIT Press.

LEWIS, C. S. (1960). Studies in Words. Cambridge: Cambridge University Press.

LI, C. N. (Ed.). (1976). Subject and Topic. New York: Academic Press.

LOWE, R. (1994). Introduction à la psychoméchanique du langage. Québec: Fonds Gustave Guillaume, Université Laval.

LUMSDEN, M. (1988). Existential Sentences: Their Structure and Meaning. London: Croom Helm.

LYONS, J. (1967). A note on possessive, existential and locative sentences. Foundations of Language, 3, 390-396.

LYONS, J. (1991). Natural Language and Universal Grammar: Essays in Linguistic Theory (1), Cambridge: Cambridge University Press.

LYONS, J. (1995). Linguistic Semantics. Cambridge: Cambridge University Press.

MARTIN, R. (1981). Thème et thématisation de l'énoncé. Travaux de Linguistique, 8, 27-48. 
McCAWLEY, J. D. (Ed.). (1976). Syntax and semantics 7: Notes from the linguistic underground. New York: Academic Press.

McCLOSKEY, J. M. (1991). There, it and agreement. Linguistic Inquiry, 22 (3), 563-567.

MERRIAM-WEBSTER'S. (1989). Dictionary of English Usage. Springfield, Massachussetts: Merriam Webster's.

MÉRY, R. (1994). L'inversion sujet/auxiliaire en anglais sans antéposition d'un tiers élément, Sigma, 16, 19-57.

MICHAELIS, L. A. (1993). 'Continuity' within three scalar models: The polysemy of the adverbial still. Journal of Semantics, 10, 193-237.

MILSARK, G. L. (1977). Toward an explanation of certain pecularities of the existential construction in English. Linguistic Analysis, 3 (1), 1-29.

MILSARK, G. L. (1979a). [Review of the book The English existential]. Studies in Languages, 3 (1), 99-108.

MILSARK, G. L. (1979b). Existential Sentences in English. New York: Garland.

MOREL, M., \& DANON-BOILEAU, L. (Eds.). (1990). Introduction, presentation, épilogue. La deixis (pp. 9-25, 627-640). Paris: Presses Universitaires de France. 
MORTON, A. G., \& GIVON, T. (Eds.). (1995). Coherence in Spontaneous Text. Philadelphia: John Benjamins.

NEVALAIMEN, T. (1987). Adverbial focusing and intonation. Lingua, 73, 141-165.

NILSEN, D. L. F. (1972). English Adverbials. The Hague: Mouton.

ONIONS, C.T. (1966). The Oxford English Dictionary of English Etymology. Oxford: Clarendon Press.

PENELOPE, J. (1982). Topicalization: The rhetorical strategies it serves and the interpretive strategies it imposes. Linguistics, 20, 683-695.

PENHALLURICK, J. (1984). Full verb inversion in English. Australian Journal of Linguistics, 4, 33-56.

PRIESTLEY, J. (1969-reprint edition). The Rudiments of English Grammar. Menston, England: The Scholar Press. (Original work published 1761).

QUIRK, R., GREENBAUM, S. et al. (1985). A Comprehensive Grammar of the English Language. New York: Longman.

RANDO, E., \& NAPOLI, D. J. (1978). Definites in there-sentences. Language, 54 (2), 301-313. 
RISSANEN, M. (1986). Variation and the study of English historical syntax. In: D. Sandkoff (Ed.), Diversity and Diachrony (pp. 97-110). Philadelphia: John Benjamins.

RIVIÈRE, N. (1992-93). Il y a: il y a 10 ans, il y a 10 ans que, depuis 10 ans. Modèles Linguistiques, 27 (1), 121-152.

ROULLAND, D. (1986). Réflexion sur la notion du signe: Gustave Guillaume comme représentant d'une école française (?). Modèles Linguistiques, 8 (2), 47-59.

SAMPSON, G. (1972). There1, There2. Journal of Linguistics, 8, 111-117.

SASAKI, M. (1991). An analysis of sentences with non-referential there in spoken American English. Word, 422 (2), 157-178.

SHEINTUCH, G. (1980). The there-insertion construction in English: A pragmatic strategy for promoting certain syntactic structures. Glossa, 4, 168-188.

SINCLAIR, J. et al. (1988). Collin's Cobuild English Language Dictionary. New York: William Collins and Sons.

SMITH, J. C. (1988). Deixis et personne en français. Sigma, 12, 1-14.

SORENSEN, K. (1981). Some observations on pronominalisation. English Studies, 62 (2), 146155. 
SPARKS, R. (1984). Here's a few more facts. Linguistic Inquiry, 15 (1), 179-183.

STEVENSON, R.J., \& VITKOVITCH, M. (1986). The comprehension of anaphoric relations. Language and Speech, 29 (4), 335-360.

STRANG, B. M. H. (1970). A History of English. London: Methuen \& Company.

SWAN, M. (1984). Practical English Usage. Oxford: Oxford University Press.

SWANNELL, J. 1992). The Oxford Modern English Dictionary. Oxford: Clarendon Press.

SWEET, H. (1898). New English Grammar (Part I \& II). London: Oxford University Press.

TASMOWSKI DE RYCK, L., \& VERLUYTEN, S. P. (1985). Control mechanisms of anaphora. Journal of Semantics, 4, 341-370.

TENNY, C. (1995). [Review of the book English verb classes and alternations: A preliminary investigation]. Language, 71 (1), 144-145.

THATCHER, V., \& McQUEEN, A. (1952). The New Webster's Encyclopedic Dictionary of the English language. Chicago: Consolidated Books.

THOMPSON, A.J., \& MARTINET, A.V. (1991). A Practical English Grammar. New York: Oxford University Press. 
TRASK, R.L. (1993). A Dictionary of Grammatical Terms in Linguistics. New York: Routledge.

VAN DEEMETER, K. (1990). Forward references in natural language. Journal of Semantics, 7 (3), 281-300.

VISSER, F. T. (1963-1973). An Historical Syntax of the English Language. Leiden: Brill.

VOGELEER, S. (1987). Le concept de point de vue et son application aux phrases existentielles qui ouvrent un text narratif. Le Langage et l'Homme, 22 (1), 26-32.

WARD, G., \& BIRNER, B. (1995). Definiteness and the English existential. Language. 71 (4), 722-742.

WARD, G., \& BIRNER, B. (1997). Response to Abbott. Language. 73 (1), 109-112.

WEBSTER, N. (1828). An American Dictionary of the English Language (Vol. II.). New York: S.Converse.

WEINER, E. S. C., \& HAWKINS, J. M. (1985). The Oxford Guide to the English Language. Oxford: Oxford University Press.

WEISSENBORN, W., \& KLEIN, W. (Eds.). (1982). Introduction. Here and There: Crosslinguistic Studies on Deixis and Demonstration (pp. 1-12), (Pragmatics Beyond, III). Amsterdam: John Benjamins. 
WIESE, B. (1983). Anaphora by pronouns. Linguistics, 21, 373-417.

WILLIAMS, J. M. (1975). Origins of the English Language: A Social and Linguistic History. New York: The Free Press.

YULE, G. (1982). Interpreting anaphora without identifying reference. Journal of Semantics, 1 (4), 315-322.

ZANDVOORT, R.W. (1972). A Handbook of English Grammar. London: Longman.

ZIV, Y. (1982). Getting more mileage out of existentials in English. Linguistics, 20, 747-762.

ZUBIN, D. A., CHOI, S. (1984). Orientation and gestalt: conceptual organizing principles in the lexicalization of space. Papers from the Parasession on Lexical Semantics, Chicago Linguistic Society, 333-345. 


\section{SOURCES OF TOKENS}

The sources from which all tokens were taken are indicated with a single asterisk and those from which all tokens were taken from the first 100 pages are marked with double asterisks.

*BIANCO, M. J. (1994). The Velveteen Rabbit. Minnesota: Creative Editions.

**CHOY, W. (1995). The Jade Peony. Vancouver: Douglas and McIntyre.

DÖBLIN, A. (1992). Destiny's Journey. New York: Paragon House.

FUNSTON, S. (1996). Scary Science. Toronto: Owl Books.

**GOLDEN, A. (1997). Memoirs of a Geisha. New York: Alfred A. Knopf.

**GOLDING, L. (1939). Mr. Emmanuel. New York: Popular Library.

*JOOSE, B. M. (1991). Mama, Do You Love Me?. San Francisco: Chronicle Books.

SCHULMAN, J. (1998). The 20 th Century Children's Book Treasury. New York: Alfred A. Knopf.

WONG, J. (1996). Red China Blues. Toronto: Doubleday/Anchor Books. 
YE, T. X. (1997). A Leaf in the Bitter Wind. Toronto: Doubleday. 